\title{
Continuous Estimation of Annual Committed Effective Dose of Radioactive Cesium by Market Basket Study in Japan from 2013 to 2019 after Fukushima Daiichi Nuclear Power Plant Accident
}

\author{
Hiromi Nabeshi ${ }^{1}$, Tomoaki Tsutsumi ${ }^{1}$, Masataka Imamura1 ${ }^{1}$, Yoshinori Uekusa ${ }^{1,2}$, \\ Akiko Hachisuka $^{3}$, Rieko Matsuda ${ }^{1,4}$, Reiko Teshima ${ }^{1,5}$, Hiroshi Akiyama ${ }^{1}$ \\ ${ }^{1}$ Division of Foods, National Institute of Health Sciences, Kanagawa, Japan 3-25-26 Tonomachi, Kawasaki-ku, \\ Kawasaki, Kanagawa 210-9501, Japan \\ ${ }^{2}$ Division of Natural Medicines, Faculty of Pharmacy, Keio University, Tokyo, Japan 1-5-30 Shibakoen, Minato- \\ ku, Tokyo 105-8512, Japan \\ ${ }^{3}$ Division of Biochemistry, National Institute of Health Sciences, Kanagawa, Japan 3-25-26 Tonomachi, \\ Kawasaki-ku, Kawasaki, Kanagawa 210-9501, Japan \\ ${ }^{4}$ Division of Food Safety Information, National Institute of Health Sciences, Kanagawa, Japan 3-25-26 \\ Tonomachi, Kawasaki-ku, Kawasaki, Kanagawa 210-9501, Japan \\ ${ }^{5}$ Faculty of Veterinary Medicine, Okayama University of Science, Ehime, Japan 1-3 Ikoinooka, Imabari, Ehime \\ 794-8555, Japan
}

\begin{abstract}
Radionuclide contamination in foods has been a great concern after the Fukushima Daiichi Nuclear Power Plant (FDNPP) accident. To estimate time trends of daily intake and annual committed effective dose of radionuclides after the accident, radioactive cesium $\left(\mathrm{r}-\mathrm{Cs} ;{ }^{134} \mathrm{Cs}\right.$ and $\left.{ }^{137} \mathrm{Cs}\right)$ and potassium-40 $\left({ }^{40} \mathrm{~K}\right)$ in market basket $(\mathrm{MB})$ samples prepared at 6 -month intervals in periods from September 2013 to March 2019 in 15 regions of Japan were analyzed using $\gamma$-ray spectrometry. The annual committed effective dose of $\mathrm{r}$-Cs, calculated at non-detected radionuclide levels assumed to be half the limit of detection (LOD), appeared to decrease gradually in 11 regions close to the FDNPP that were more likely to be affected by the accident. Differences in doses among the 15 regions were large just after the accident, but gradually decreased. In particular, ${ }^{134} \mathrm{Cs}$ has not been detected in any MB sample in any region since September 2018, and annual committed effective dose from ${ }^{134} \mathrm{Cs}$ in all regions was mostly constant at around $0.3 \mu \mathrm{Sv} /$ year (given the respective LODs). The maximum annual committed effective dose of r-Cs in this study was decreased from $2.7 \mu \mathrm{Sv} /$ year in September 2013 to $1.0 \mu \mathrm{Sv} /$ year in March 2019. In contrast, the range of annual committed effective dose of ${ }^{40} \mathrm{~K}$ varied from approximately 150 to $200 \mu \mathrm{Sv} /$ year during that time frame and did not change much throughout the period of this study. Although annual committed effective doses
\end{abstract}

Received: 7 August 2020; Accepted: 25 October 2020; Published online: 25 December 2020

Corresponding author: Hiromi Nabeshi, Division of Foods, National Institute of Health Sciences, Kanagawa, Japan 3-25-26 Tonomachi, Kawasaki-ku, Kawasaki, Kanagawa 210-9501, Japan (nabeshi@nihs.go.jp)

The contents of this article reflect solely the view of the author(s).

Abbreviations: ${ }^{40} \mathrm{~K}$ : potassium-40, ${ }^{131} \mathrm{I}$ : iodine-131, ${ }^{133} \mathrm{Xe}$ : xenon-133, ${ }^{134} \mathrm{Cs}$ : cesium-134, ${ }^{137} \mathrm{Cs}$ : cesium-137, CODEX: Codex Alimentarius Commission, FDNPP: Fukushima Daiichi Nuclear Power Plant, GEMS: Global Environmental Monitoring System, HPGe: highpurity Germanium, MB: market basket, MHLW: the Ministry of Health, Labour and Welfare, LOD: limit of detection, NISA: Nuclear and Industrial Safety Agency.

Suggested citation: Hiromi Nabeshi, Tomoaki Tsutsumi, Masaaki Imamura, et al. Continuous Estimation of Annual Committed Effective Dose of Radioactive Cesium by Market Basket Study in Japan from 2013 to 2019 after Fukushima Daiichi Nuclear Power Plant Accident. Food Safety. 2020; 8 (4) 97-114. doi: 10.14252/foodsafetyfscj.D-20-00017

(c) (i) Open Access This article is an open access article distributed under the term of the Creative Commons Attribution 4.0 International License. 
of r-Cs in regions close to the FDNPP appeared to be higher than in regions far from the FDNPP, doses in all regions are remaining at a much lower levels than the intervention exemption level, $1 \mathrm{mSv} / \mathrm{year}$, in foods in Japan.

Key word: annual committed effective dose, daily intake, Fukushima Daiichi Nuclear Power Plant accident, market basket, radioactive cesium

\section{Introduction}

The Fukushima Daiichi Nuclear Power Plant (FDNPP) accident happened on March 2011 due to the tsunami triggered by the Tohoku earthquake. After the accident, several different types of radionuclides were released from the FDNPP into the surrounding environment. According to a report released by the Nuclear and Industrial Safety Agency $(\mathrm{NISA})^{1)}$, these radionuclides included xenon-133 $\left({ }^{133} \mathrm{Xe}\right.$; approximately $1.1 \times 10^{19} \mathrm{~Bq}$ ), iodine-131 ( ${ }^{131} \mathrm{I}$; approximately $\left.1.6 \times 10^{17} \mathrm{~Bq}\right)$, cesium-134 $\left({ }^{134} \mathrm{Cs}\right.$; approximately $1.8 \times 10^{16}$ $\mathrm{Bq})$, and cesium-137 $\left({ }^{137} \mathrm{Cs}\right.$; approximately $\left.1.5 \times 10^{16} \mathrm{~Bq}\right)$. Although the released total quantities of ${ }^{133} \mathrm{Xe},{ }^{131} \mathrm{I}$, and ${ }^{132} \mathrm{Te}$ were substantially large for a short time after the accident, the half-lives of these radionuclides are very short (less than 10 days $)^{2}$. Therefore, one year after the FDNPP accident, the largest remaining amounts in the environment are thought to be mainly ${ }^{134} \mathrm{Cs}$ and ${ }^{137} \mathrm{Cs}$. However, since large quantities of radionuclides were released and remain in the environment, many foodstuffs were directly or indirectly contaminated with radionuclides.

Responding to this situation, the government of Japan immediately established provisional regulatory values and started to regulate the distribution of foods contaminated with radionuclide amounts that exceeded those values to ensure food safety ${ }^{3}$. In April 2012, new standard limits were established for foods $(10,50$, and $100 \mathrm{~Bq} / \mathrm{kg}$ for drinking water, milk and infant foods, and general foods, respectively, as the concentration of radioactive cesium $[\mathrm{r}-\mathrm{Cs}$; the sum of ${ }^{134} \mathrm{Cs}$ and $\left.{ }^{137} \mathrm{Cs}\right]$ ) by the Ministry of Health, Labour and Welfare (MHLW) based on risk assessments by the Food Safety Commission in Japan ${ }^{4}$. These standard limits were set to avoid exceeding the intervention exemption level of the Codex Alimentarius Commission (CODEX), $1 \mathrm{mSv} /$ year, a level considered as safe for the public.

Monitoring the level of $\mathrm{r}-\mathrm{Cs}$ in foods has continued by local governments to avoid distributing foods contaminated with r-Cs levels higher than the standard limits. To confirm the validity of the risk management, it is important to understand actual situations about $\mathrm{r}$-Cs internal exposure dose from foods. However, because r-Cs concentration in foods is probably changed by processing or cooking ${ }^{5-9)}$, concentrations of radionuclides in uncooked foods, which are the main targets of monitoring, are not necessarily directly reflected to dietary intake. Therefore, to estimate more realistic dietary intake of r-Cs, it is necessary to consider the possibility of $\mathrm{r}$-Cs concentration change by processing or cooking.

To estimate the dietary intake of radionuclides, especially r-Cs, many surveys have been conducted after the FDNPP accident ${ }^{10-15)}$, and a review of internal exposure dose based on results from these surveys was published ${ }^{16)}$. We also reported on daily intake and annual committed effective dose of r-Cs using a market basket (MB) study design ${ }^{17,18)}$. Previous studies including our survey suggested that annual committed effective dose of r-Cs in Japan was sufficiently lower than the intervention exemption level, $1 \mathrm{mSv} / \mathrm{year}$. The time periods in these surveys were mainly within three years after the FDNPP accident, and the dietary intake of r-Cs estimated at the end of these short periods might not exactly reflect the influence of $\mathrm{r}-\mathrm{Cs}$ contamination in foods because some of the foods contaminated by $\mathrm{r}-\mathrm{Cs}$ released by the accident, such as processed foods, might have not yet been distributed. Long-term transitional changes in dietary intake of $\mathrm{r}$-Cs have not yet been reported. To consider these issues, continuous surveys across wide areas have been required. In addition, it would be important to monitor daily intake and annual committed effective dose of r-Cs because those reflect $\mathrm{r}$-Cs concentrations in commercial foods in Japan. Therefore, continuous surveys of dietary intake of r-Cs are necessary to evaluate the effects of food regulations resulting from standard limits on $\mathrm{r}-\mathrm{Cs}$.

In this study, to evaluate the time trends of dietary intake of r-Cs, particularly concerned radionuclides after the FDNPP accident, we estimated daily intake and annual committed effective dose of $\mathrm{r}$-Cs by analyzing MB samples derived from 15 regions in Japan during the periods from September 2013 to March 2019. For comparison, we also estimated daily intake and annual committed effective dose of potassium-40 $\left({ }^{40} \mathrm{~K}\right)$, which is a representative natural radionuclide. Our findings were then compared to the results of surveys reported before the FDNPP accident.

\section{Materials and Methods}

\subsection{Materials and Methods}

MB samples were prepared twice a year, in March periods (Mar-) and in September periods (Sep-), from September 2013 to March 2019. Based on the 2008-2010 (study period from Sep-2013 to Mar-2016) and the 2011-2013 (study period from Sep-2016 to Mar-2019) results from the National Health 




Fig. 1. Fifteen regions in Japan where MB samples were prepared. Filled 15 regions on the map are subject regions of $\mathrm{r}-\mathrm{Cs}$ intake survey. Filled circle indicates location of the FDNPP.

and Nutrition Examination Survey ( $\geq 1$ year of age) in Japan, types of foods and daily food consumption data used in the present study were decided by each region. The foods were purchased from local supermarkets in each of the 15 regions (three areas in Fukushima [Nakadori, Hamadori, Aizu], Iwate, Miyagi, Tochigi, Ibaraki, Saitama, Tokyo, Kanagawa, Niigata, Hokkaido, Osaka, Kochi, and Nagasaki, as shown in Fig. 1). To estimate annual committed effective dose in the MB sample when locally produced foods were consumed preferentially, locally produced foods were selected as ingredients of MB samples, especially the fresh foods category that included fruits, vegetables, and fish, to the extent possible. If unable to purchase locally-produced foods, neighboring area-produced foods and domestic foods were preferentially selected. All foods purchased were classified into the following 13 categories summarized in Table 1; category 1 , rice and rice products ( 3 kinds of food); category 2 , cereals, potatoes, and nuts (29 kinds of food); category 3 , sugar and confectioners (12 kinds of food); category 4 , oil and fats (5-6 kinds of food); category 5, beans and their products (10-11 kinds of food); category 6 , fruits (11 kinds of food); category 7 , colored vegetables ( 9 kinds of food); category 8 , vegetables, mushrooms, and seaweeds (15 kinds of food); category 9, alcohol and beverages (10 kinds of food); category 10, fishes and shellfishes (24-25 kinds of food); category 11, meats and eggs (13-14 kinds of food); category 12, milk and milk products (7 kinds of food); and category 13, seasonings and spices (12 kinds of food). Tap water was used as drinking water (category 14). These categories were used for estimation of dietary intake of contaminants such as dioxins ${ }^{19}$. Foods were weighted in proportion to the amount of daily consumption by each region. Foods were washed, peeled, and cooked easily such as by boiling and stir-frying without oil and seasoning, according to Japanese eating habits. Foods were then mixed well in a blender without adding water, by each food category and each region. All the prepared MB samples (total 210; 15 regions $\times 14$ food categories) were stored below $-20^{\circ} \mathrm{C}$ until the analysis. 
Table 1. Classification of food categories in MB samples

\begin{tabular}{cll}
\hline No & Category & Examples of food item \\
\hline 1 & Rice and rice products & White rice, Rice cake, etc. \\
2 & Cereals, potatoes and nuts & Bread, Noodle, Corn, Potato, Peanuts, etc. \\
3 & Sugar and confectioners & Sugar, Japanese sweets, Donuts, Chocolate, Potatochip, etc. \\
4 & Oil and fats & Butter, Margarine, Vegetable oil, Lard, etc. \\
5 & Beans & Boiled soybean, Tofu, Natto, Azuki bean, etc. \\
6 & Fruits & Strawberry, Apple, Kiwi, Mandarin orange, etc. \\
7 & Colored vegetables & Tomato, Carrot, Spinach, Pumpkin, etc. \\
8 & Other vegetables, mushrooms and seaweeds & Cabagge, Cucumber, Japanese radish, Nameko mushroom, Laver, etc. \\
9 & Alcohol and beverages & Japanese sake, Beer, Wine, Green tea, Coffee, Coke, etc. \\
10 & Fishes and shellfishes & Mackerel, Flatfish, Tuna, Squid, Shrimp, Scallop, Fish sausage, etc. \\
11 & Meats and eggs & Beef, Pork, Chcikin, Eggs, etc. \\
12 & Milk and milk products & Cow's milk, Yogurt, Cheese, Cream, etc. \\
13 & Seasonings and spices & Soy sauce, Salt, Miso, Pepper, etc. \\
14 & Drinking water & Tap water \\
\hline
\end{tabular}

\subsection{Determination of ${ }^{134} \mathrm{Cs},{ }^{137} \mathrm{Cs}$, and ${ }^{40} \mathrm{~K}$}

Radioactive Cs (r-Cs; ${ }^{134} \mathrm{Cs}$, and ${ }^{137} \mathrm{Cs}$ ) and ${ }^{40} \mathrm{~K}$ in all prepared MB samples (15 regions in 12 periods) was measured by a high-purity Germanium (HPGe) $\gamma$-spectrometer (GC4019; Canberra, Meriden, CT, USA). Each sample was filled into a $2 \mathrm{~L}$ Marinelli container and measured for 22 hrs. Analytical software (Gamma Explorer; Canberra) was used to calculate $\mathrm{r}-\mathrm{Cs}$ and ${ }^{40} \mathrm{~K}$ concentrations from the HPGe $\gamma$-spectrometer data. Matrix was set to "water", and self-absorption was corrected. Results were corrected for the background (from a measurement conducted for $48 \mathrm{hrs}$ ), the sum effect, and the attenuation (reference date was the date of sample preparation). Because ${ }^{134} \mathrm{Cs}$ emits several different energy gamma-rays, concentration of ${ }^{134} \mathrm{Cs}$ was calculated using load average concentration from peaks of 475.4, 563.3, 569.3, 604.7, 795.8, 801.8, 1038.5, 1167.9, and $1365.1 \mathrm{keV}^{20)}$. Concentrations of ${ }^{137} \mathrm{Cs}$ and ${ }^{40} \mathrm{~K}$ were calculated using counts from peaks of $661.6 \mathrm{keV}$ and $1460.75 \mathrm{keV}$, respectively. The detector was regularly calibrated using a gamma ray reference source purchased from the Japan Radioisotope Association (Tokyo, Japan). Peak area was calculated by an extension method or function adjustment method, depending on the peak shape. The concentration of $\mathrm{r}$-Cs represents the sum of concentration of ${ }^{134} \mathrm{Cs}$ and ${ }^{137} \mathrm{Cs}$. Lower limits of detection (LOD) of ${ }^{134} \mathrm{Cs},{ }^{137} \mathrm{Cs}$, and ${ }^{40} \mathrm{~K}$ were $0.028 \sim 0.098$, $0.029 \sim 0.088$, and $0.22 \sim 1.5 \mathrm{~Bq} / \mathrm{kg}$, respectively. LOD is affected by various factors such as the air dose in the measurement environment and the background in each MB sample. Because the measurement environment changed in August 2017, LODs of r-Cs and ${ }^{40} \mathrm{~K}$ in several food categories after Sep-2017 tended to be somewhat lower than those before Mar-2017.

\subsection{Calculation of Daily Intake and Annual Committed Effective Dose of $r-C s$ and ${ }^{40} \mathrm{~K}$}

The daily intake of each radioactive nuclide in each category was determined by multiplying the concentration of each radioactive nuclide by food consumption. The daily intake of each radioactive nuclide in each region was calculated as the sum of all categories (categories 1 to 14). If the concentration of each radioactive nuclide was lower than each LOD $(=\mathrm{ND})$, half value of LOD (1/2LOD) was used as the concentration for calculation of daily intake. According to the recommended method by Global Environmental Monitoring System (GEMS) for handling data on foods with low levels of contamination, in food categories with concentrations lower than LOD ${ }^{21)}$, if the data set contains more than $60 \%$ of data that is higher than LOD, all data lower than LOD are calculated as 1/2LOD. Taking data continuity into account, annual committed effective dose of r-Cs was calculated by the same method used before 2013, although detection rates for $\mathrm{r}-\mathrm{Cs}$, especially ${ }^{134} \mathrm{Cs}$, were below $60 \%$ since 2013 . The daily intake per person in each region was calculated using the following equation:

$$
D k(\mathrm{~Bq} / \mathrm{person} / \mathrm{day})=\sum_{i=1}^{14}(\mathrm{C} k i \times \mathrm{M} i)
$$

where $k$ is the radionuclide, $\mathrm{D} k$ is the daily intake of the radionuclide $k$ per person, $i$ is the individual food category, $\mathrm{C} k i$ $(\mathrm{Bq} / \mathrm{kg})$ is concentration of radionuclide $k$ in food category $i$, and $\mathrm{M} i(\mathrm{~kg} / \mathrm{day})$ is the daily consumption of food category $i$.

The annual committed effective doses of each radionuclide were calculated using the following equation, assuming that the daily intake of radioactive nuclides was constant throughout the year: 


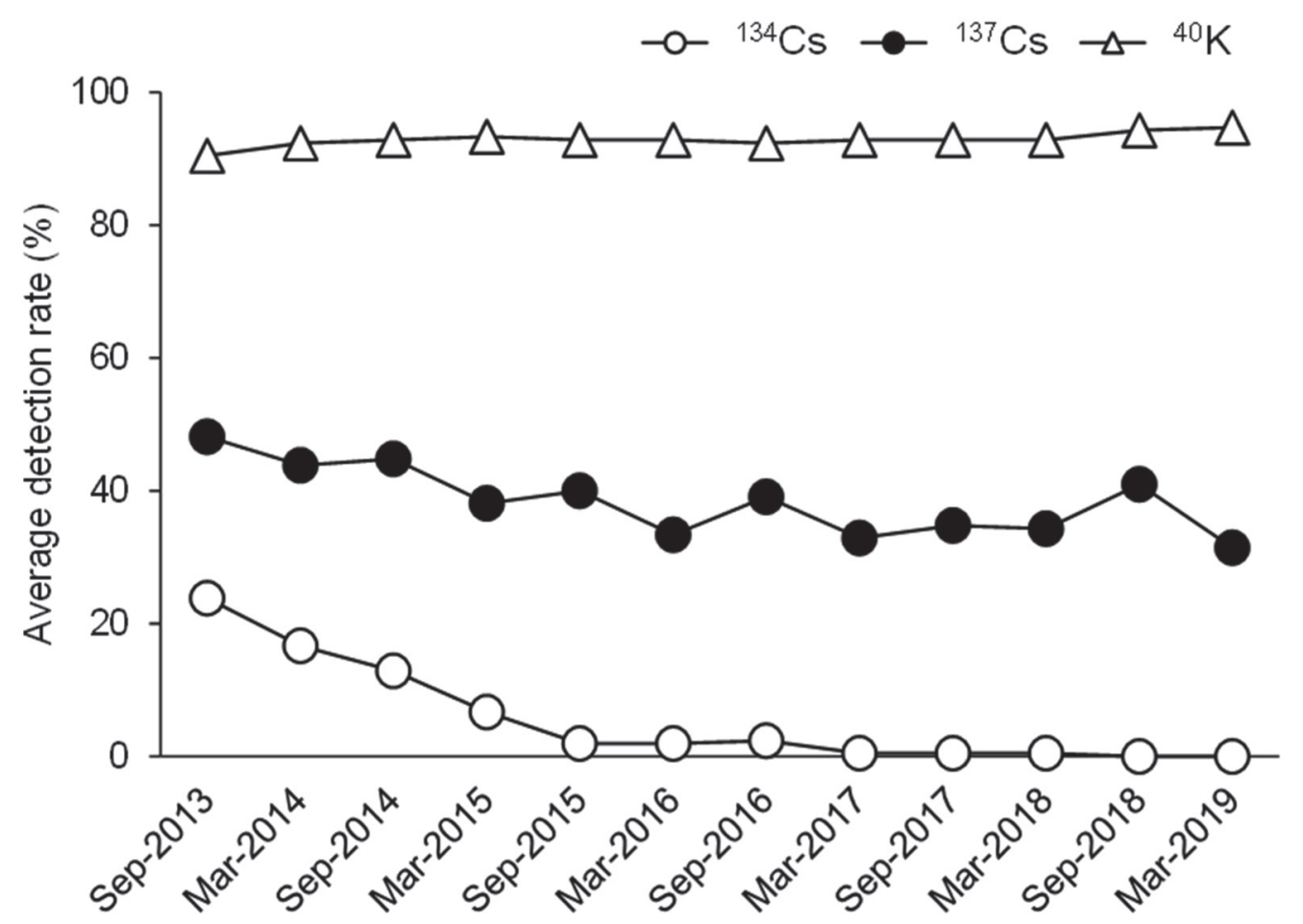

Fig. 2. Time trends of average detection rates for ${ }^{134} \mathrm{Cs},{ }^{137} \mathrm{Cs}$, and ${ }^{40} \mathrm{~K}$. Opened circles, filled circles, and opened triangles indicate average detection rates for ${ }^{134} \mathrm{Cs},{ }^{137} \mathrm{Cs}$, and ${ }^{40} \mathrm{~K}$, respectively.

$\mathrm{E} k(\mu \mathrm{Sv} / \mathrm{person} / \mathrm{year})$

$=\mathrm{D} k(\mathrm{~Bq} /$ person/day $) \times \mathrm{A} k(\mu \mathrm{Sv} / \mathrm{Bq}) \times 365($ days $)$

where $\mathrm{E} k$ is the annual committed effective dose of radionuclide $k$, and $\mathrm{A} k$ is committed effective coefficients for radionuclide $k$ by ingestion. The committed effective coefficients for adults obtained were $1.9 \times 10^{-2} \mu \mathrm{Sv} / \mathrm{Bq}$ for ${ }^{134} \mathrm{Cs}, 1.3 \times$ $10^{-2} \mu \mathrm{Sv} / \mathrm{Bq}$ for ${ }^{137} \mathrm{Cs}$, and $6.2 \times 10^{-3} \mu \mathrm{Sv} / \mathrm{Bq}$ for ${ }^{40} \mathrm{~K}^{22)}$.

\section{Results and Discussion}

\subsection{Detection Rates and Concentrations of $\mathrm{r}$-Cs and ${ }^{40} \mathrm{~K}$ in MB Samples}

We investigated the time trends of detection rates and concentrations of $\mathrm{r}$-Cs and ${ }^{40} \mathrm{~K}$ in $\mathrm{MB}$ samples. From the total of $210 \mathrm{MB}$ samples (15 regions $\times 14$ food categories) analyzed in each period, the average detection rates for ${ }^{134} \mathrm{Cs},{ }^{137} \mathrm{Cs}$, and ${ }^{40} \mathrm{~K}$ are shown in Fig. 2. The detection rate for ${ }^{134} \mathrm{Cs}$ decreased substantially from $24 \%$ to $0 \%$ during the 5.5 -year duration of this study. The detection rate for ${ }^{137} \mathrm{Cs}$ also decreased from $48 \%$ to $31 \%$, although this decrease was slower than that for ${ }^{134} \mathrm{Cs}$. The difference in the rate decrease between ${ }^{134} \mathrm{Cs}$ and ${ }^{137} \mathrm{Cs}$ was thought to be due to a difference in their half-lives. The physical half-life of ${ }^{134} \mathrm{Cs}$, approximately 2 years, is markedly shorter than that of ${ }^{137} \mathrm{Cs}$, which is approximately 30 years ${ }^{2}$. Therefore, according to an example calculation based on physical half-life, the amount of ${ }^{134} \mathrm{Cs}$ residue in 2013 and 2019 is estimated to be approximately $50 \%$ and $6 \%$, respectively, compared with the total amount of released ${ }^{134} \mathrm{Cs}$ at the time of the FNDPP accident, whereas the amount of ${ }^{137} \mathrm{Cs}$ residue in 2013 and 2019 is estimated to be approximately $95 \%$ and $83 \%$, respectively. Thus, the difference between amount of residue for ${ }^{134} \mathrm{Cs}$ and ${ }^{137} \mathrm{Cs}$ is getting larger over time and is related to time trends of the detection rates for ${ }^{134} \mathrm{Cs}$ and ${ }^{137} \mathrm{Cs}$.

Fig. 3 shows time trends of the detection rate for $\mathrm{r}-\mathrm{Cs}$ in each region. Regions close to the FDNPP including Fukushima (Nakadori, Hamadori, Aizu), Iwate, Miyagi, Tochigi, Ibaraki, Saitama, Tokyo, Kanagawa, and Niigata were defined as near-FDNPP regions, and regions far from the FDNPP including Hokkaido, Osaka, Kochi, and Nagasaki were defined as far-FDNPP regions. The results indicated that there were regional differences in the detection rates for $\mathrm{r}-\mathrm{Cs}$ and associated time trends. The detection of ${ }^{134} \mathrm{Cs}$ in the near-FDNPP regions except Niigata gradually decreased, it was not detected in any region after Sep-2018, and it was never detected in the far-FDNPP regions except Osaka during the study period (Fig. 3A). The detection rate for ${ }^{137} \mathrm{Cs}$ appeared to be higher in the near-FDNPP regions compared with the far-FDNPP regions, which were constantly low (approximately $30 \%$ lower) during the 5.5 -year duration of this study (Fig. 3B). The detection rate for ${ }^{137} \mathrm{Cs}$ in Fukushima (Hamadori), Miyagi, Ibaraki, Saitama, and Kanagawa appeared to gradually decrease. Meanwhile, the detection rates 


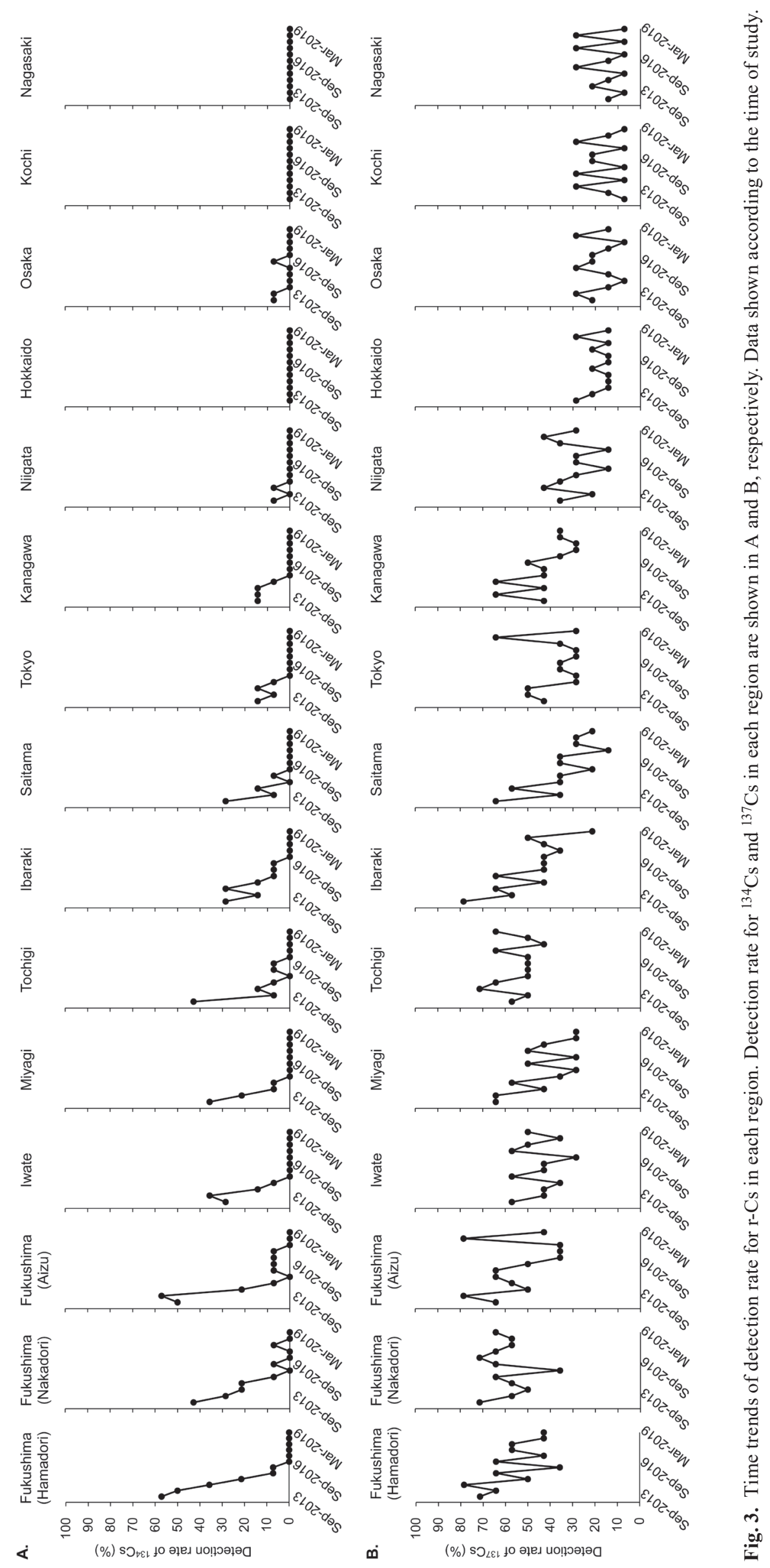




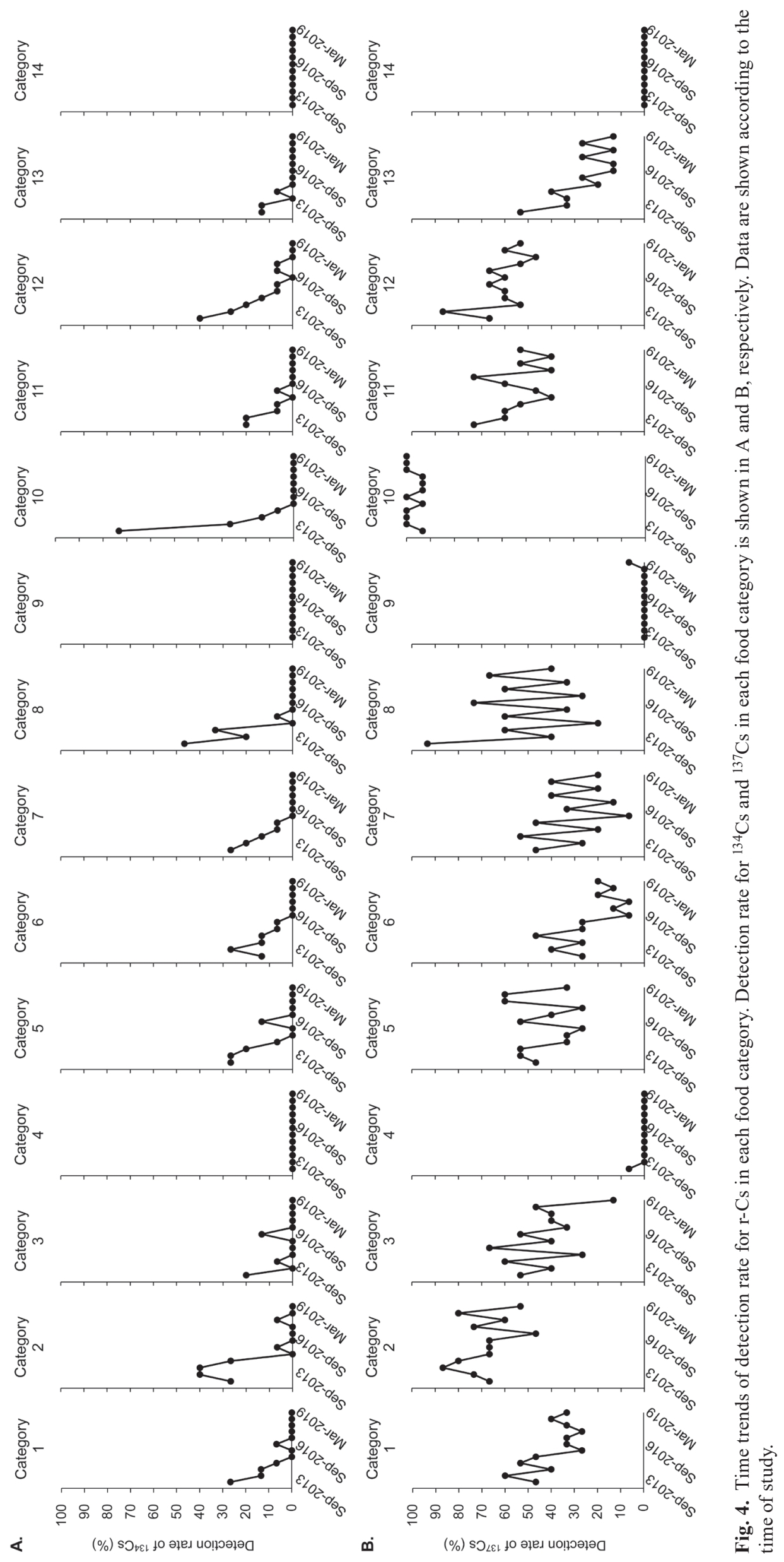


for ${ }^{137} \mathrm{Cs}$ in the other near-FDNPP regions did not appear to decrease until March 2019.

Time trends for the detection rate for $\mathrm{r}-\mathrm{Cs}$ in each food category during this study appeared to follow two patterns: one decreased gradually, and the other did not change (Fig. 4). The detection rates for ${ }^{134} \mathrm{Cs}$ in all categories except 4, 9, and 14 decreased rapidly compared with ${ }^{137} \mathrm{Cs}$, which was likely a result of the difference in physical half-life between ${ }^{134} \mathrm{Cs}$ and ${ }^{137} \mathrm{Cs}$. The presence of ${ }^{134} \mathrm{Cs}$ was detected only in categories 2 and 12 since Sep-2016, and was not detected in any category since Sep-2018 (Fig. 4A). The detection rate for ${ }^{137} \mathrm{Cs}$ in categories $1,3,6,11,12$, and 13 appeared to decrease gradually during the study, while the detection rate in categories 2, 5, 7, 8, and 10 did not appear to decrease (Fig. 4B). The detection rate for ${ }^{137} \mathrm{Cs}$ in categories 2, 10, 11, and 12 was over $50 \%$ in most cases throughout this study, especially in category 10 , which consisted of fishes and shellfishes and had a detection rate of more than $90 \%$. A similar tendency was reported in a study conducted by Sugiyama et $\mathrm{al}^{23}$ ) before the FDNPP accident. This suggests that although the influence of global fallout and the Chernobyl nuclear accident remained in all food categories, their influence on category 10 was severer than other food categories. According to calculations based on the physical half-life of ${ }^{137} \mathrm{Cs}$, approximately $45 \%$ of total ${ }^{137} \mathrm{Cs}$ released by the Chernobyl nuclear accident in 1986 is assumed to still remain in the environment in 2019. Because the detection rate in category 10 was high and the regional difference was small, we considered that category 10 in our study contained ${ }^{137} \mathrm{Cs}$ that was derived from global fallout and the Chernobyl nuclear accident as well as from the FDNPP accident. Although the detection rate in category 10 remained high during this study, the average concentration of r-Cs in category 10 decreased year by year (data not shown). Conversely, $\mathrm{r}-\mathrm{Cs}$ in categories 4, 9, and 14 was never detected except for ${ }^{137} \mathrm{Cs}$, which was detected only once in categories 4 and 9. Category 4 consisted of oils and fats. Since Cs are present as hydrophilic compounds, it is difficult to transfer from ingredients to oil and fats ${ }^{24)}$. In addition, oils are often made from imported ingredients. Therefore, $r-C s$ was unlikely to be detected in category 4 in almost all cases. Categories 9 and 14 are beverages including alcohol and tap water, respectively. Since tap water and water for food manufacturing are strictly managed by Water Works and have the same standard limit as drinking water $(10 \mathrm{~Bq} / \mathrm{kg})$, r-Cs were also unlikely to be detected in categories 9 and 14 in almost all cases. On the other hand, average detection rates for ${ }^{40} \mathrm{~K}$ in all regions were always over $80 \%$ throughout the study period (Fig. 2). There was little difference in detection rates for ${ }^{40} \mathrm{~K}$ among regions, and detection rates for ${ }^{40} \mathrm{~K}$ in food categories except categories 4 (Sep-2013) and 14 were nearly

\section{0\% (Figs. S1A and S1B).}

Regional differences in average concentrations of $\mathrm{r}-\mathrm{Cs}$ were apparent, but their corresponding time trends were mostly the same in all regions (Fig. 5). Relatively high concentrations were found in Fukushima (Nakadori) and Iwate until Sep-2015 and Sep-2014, respectively (Fig. 5A). Average concentrations of ${ }^{134} \mathrm{Cs}$ in Fukushima (Nakadori) were 0.18, 0.19, 0.093, 0.15 and $0.18 \mathrm{~Bq} / \mathrm{kg}$ in Sep-2013, Mar2014, Sep-2014, Mar-2015 and Sep-2015, respectively and those in Iwate were $0.25,0.080$ and $0.12 \mathrm{~Bq} / \mathrm{kg}$ in Sep-2013, Mar-2014 and Sep-2014, respectively. After that, the concentrations decreased to less than the LODs along with other regions where ${ }^{134} \mathrm{Cs}$ was detected. Average concentrations of ${ }^{137} \mathrm{Cs}$ tended to decrease gradually in all regions (Fig. 5B). Initially, concentrations of ${ }^{137} \mathrm{Cs}$ in Fukushima, Iwate, Miyagi, and Tochigi appeared to be higher than in other regions including the far-FDNPP. However, the difference of average concentration of ${ }^{137} \mathrm{Cs}$ between these two regions became very small in Mar-2019. On the other hand, there was little difference in average concentrations of ${ }^{40} \mathrm{~K}$ among regions (Fig. S2).

\subsection{Estimates of Daily Intake and Annual Committed Effective Dose of $\mathrm{r}-\mathrm{Cs}$ and ${ }^{40} \mathrm{~K}$}

We estimated daily intake and annual committed effective dose of r-Cs $\left({ }^{134} \mathrm{Cs}\right.$ and $\left.{ }^{137} \mathrm{Cs}\right)$ and ${ }^{40} \mathrm{~K}$ in the 15 regions (Tables 2 and 3, respectively). As described earlier, if the concentration of a given radionuclide in a MB sample was less than the LOD, half of the LOD was used as the concentration for calculation purposes. Therefore, it is necessary to consider the possibility that daily intakes and annual committed effective doses of r-Cs, especially those for ${ }^{134} \mathrm{Cs}$, were likely to have been overestimated in this study. The range of estimated daily intake and annual committed effective dose in each period is summarized in Tables $\mathbf{4 A}$ and $\mathbf{4 B}$, respectively. Of note, the ranges were calculated only from quantifiable values, which means that not detected (ND) was handled as 0 . Time trends for annual committed effective doses of ${ }^{134} \mathrm{Cs}$ and ${ }^{137} \mathrm{Cs}$ in the near-FDNPP region appeared to decrease from Sep-2013 to Mar-2019, however, the rate decrease was more gradual since Mar-2017 (Fig. 6). The daily intake and annual committed effective dose of r-Cs were at maximum in Fukushima (Nakadori) and Fukushima (Hamadori) before Sep-2015. However, the region, which had the maximum daily intake and annual committed effective dose of $\mathrm{r}-\mathrm{Cs}$, changed to other regions (Tochigi and Iwate) between Mar-2016 and Sep-2017. After Mar-2018, Fukushima (Nakadori) again became the region in which daily intake and annual committed effective dose of r-Cs were at maximum. There were no substantial regional dif- 


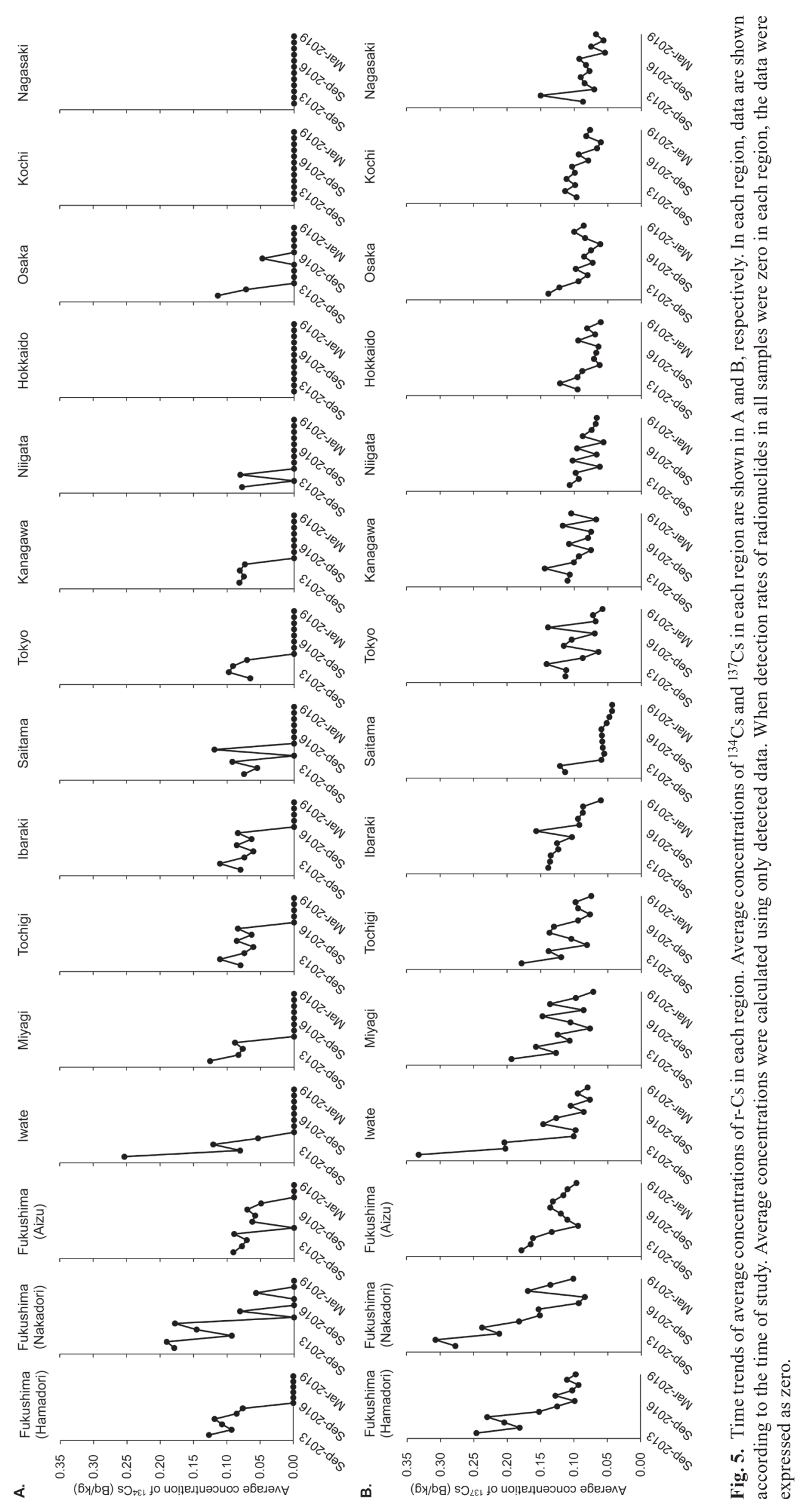


Table 2. Daily intakes (Bq/day) of ${ }^{134} \mathrm{Cs},{ }^{137} \mathrm{Cs}, \mathrm{r}-\mathrm{Cs}$, and ${ }^{40} \mathrm{~K}$ in 15 regions

\begin{tabular}{|c|c|c|c|c|c|c|c|c|c|c|c|c|}
\hline \multirow{2}{*}{ Region } & \multicolumn{12}{|c|}{${ }^{134} \mathrm{Cs}$} \\
\hline & Sep-2013 & Mar-2014 & Sep-2014 & Mar-2015 & Sep-2015 & Mar-2016 & Sep-2016 & Mar-2017 & Sep-2017 & Mar-2018 & Sep-2018 & Mar-2019 \\
\hline Fukushima (Hamadori) & 0.15 & 0.12 & 0.11 & 0.080 & 0.063 & 0.062 & 0.057 & 0.056 & 0.047 & 0.048 & 0.045 & 0.042 \\
\hline Fukushima (Nakadori) & 0.16 & 0.11 & 0.076 & 0.10 & 0.066 & 0.046 & 0.053 & 0.048 & 0.040 & 0.046 & 0.038 & 0.039 \\
\hline Fukushima (Aizu) & 0.10 & 0.093 & 0.059 & 0.054 & 0.046 & 0.052 & 0.052 & 0.055 & 0.045 & 0.041 & 0.039 & 0.039 \\
\hline Iwate & 0.13 & 0.10 & 0.072 & 0.066 & 0.057 & 0.058 & 0.057 & 0.061 & 0.052 & 0.048 & 0.043 & 0.046 \\
\hline Miyagi & 0.15 & 0.065 & 0.075 & 0.061 & 0.056 & 0.057 & 0.057 & 0.059 & 0.050 & 0.047 & 0.045 & 0.045 \\
\hline Tochigi & 0.087 & 0.077 & 0.058 & 0.056 & 0.049 & 0.055 & 0.065 & 0.053 & 0.042 & 0.041 & 0.041 & 0.040 \\
\hline Ibaraki & 0.083 & 0.070 & 0.072 & 0.054 & 0.053 & 0.052 & 0.054 & 0.053 & 0.045 & 0.044 & 0.042 & 0.042 \\
\hline Saitama & 0.078 & 0.056 & 0.080 & 0.054 & 0.070 & 0.058 & 0.064 & 0.064 & 0.056 & 0.050 & 0.046 & 0.047 \\
\hline Tokyo & 0.056 & 0.064 & 0.063 & 0.054 & 0.048 & 0.050 & 0.054 & 0.054 & 0.047 & 0.045 & 0.040 & 0.042 \\
\hline Kanagawa & 0.076 & 0.069 & 0.077 & 0.057 & 0.049 & 0.051 & 0.055 & 0.052 & 0.044 & 0.042 & 0.042 & 0.041 \\
\hline Niigata & 0.076 & 0.062 & 0.064 & 0.053 & 0.051 & 0.052 & 0.055 & 0.055 & 0.049 & 0.047 & 0.043 & 0.044 \\
\hline Hokkaido & 0.061 & 0.074 & 0.059 & 0.055 & 0.060 & 0.058 & 0.059 & 0.060 & 0.051 & 0.048 & 0.046 & 0.045 \\
\hline Osaka & 0.074 & 0.057 & 0.055 & 0.054 & 0.050 & 0.052 & 0.057 & 0.054 & 0.048 & 0.043 & 0.040 & 0.041 \\
\hline Kochi & 0.069 & 0.082 & 0.053 & 0.050 & 0.050 & 0.053 & 0.057 & 0.054 & 0.048 & 0.044 & 0.044 & 0.043 \\
\hline \multirow{2}{*}{ Nagasaki } & 0.066 & 0.062 & 0.055 & 0.053 & 0.052 & 0.050 & 0.053 & 0.054 & 0.043 & 0.040 & 0.040 & 0.041 \\
\hline & \multicolumn{12}{|c|}{${ }^{137} \mathrm{Cs}$} \\
\hline Region & Sep-2013 & Mar-2014 & Sep-2014 & Mar-2015 & Sep-2015 & Mar-2016 & Sep-2016 & Mar-2017 & Sep-2017 & Mar-2018 & Sep-2018 & Mar-2019 \\
\hline Fukushima (Hamadori) & 0.34 & 0.24 & 0.31 & 0.21 & 0.19 & 0.10 & 0.15 & 0.12 & 0.12 & 0.12 & 0.12 & 0.089 \\
\hline Fukushima (Nakadori) & 0.33 & 0.24 & 0.23 & 0.28 & 0.22 & 0.13 & 0.18 & 0.13 & 0.12 & 0.16 & 0.17 & 0.15 \\
\hline Fukushima (Aizu) & 0.23 & 0.22 & 0.14 & 0.14 & 0.12 & 0.13 & 0.12 & 0.11 & 0.11 & 0.088 & 0.15 & 0.11 \\
\hline Iwate & 0.25 & 0.22 & 0.13 & 0.12 & 0.11 & 0.13 & 0.13 & 0.086 & 0.16 & 0.091 & 0.079 & 0.10 \\
\hline Miyagi & 0.32 & 0.16 & 0.17 & 0.12 & 0.11 & 0.078 & 0.13 & 0.11 & 0.11 & 0.15 & 0.095 & 0.068 \\
\hline Tochigi & 0.20 & 0.15 & 0.17 & 0.11 & 0.12 & 0.15 & 0.19 & 0.14 & 0.10 & 0.10 & 0.15 & 0.12 \\
\hline Ibaraki & 0.18 & 0.14 & 0.15 & 0.10 & 0.15 & 0.088 & 0.15 & 0.10 & 0.088 & 0.12 & 0.088 & 0.052 \\
\hline Saitama & 0.15 & 0.10 & 0.17 & 0.10 & 0.14 & 0.068 & 0.088 & 0.10 & 0.064 & 0.064 & 0.066 & 0.079 \\
\hline Tokyo & 0.10 & 0.11 & 0.12 & 0.079 & 0.064 & 0.10 & 0.089 & 0.067 & 0.11 & 0.069 & 0.10 & 0.061 \\
\hline Kanagawa & 0.11 & 0.13 & 0.16 & 0.14 & 0.076 & 0.088 & 0.12 & 0.083 & 0.072 & 0.075 & 0.069 & 0.094 \\
\hline Niigata & 0.11 & 0.086 & 0.12 & 0.076 & 0.074 & 0.061 & 0.092 & 0.062 & 0.053 & 0.066 & 0.066 & 0.060 \\
\hline Hokkaido & 0.086 & 0.085 & 0.061 & 0.060 & 0.17 & 0.068 & 0.069 & 0.060 & 0.059 & 0.056 & 0.069 & 0.047 \\
\hline Osaka & 0.10 & 0.077 & 0.065 & 0.052 & 0.077 & 0.075 & 0.060 & 0.061 & 0.050 & 0.047 & 0.068 & 0.055 \\
\hline Kochi & 0.076 & 0.079 & 0.075 & 0.055 & 0.079 & 0.053 & 0.067 & 0.080 & 0.047 & 0.056 & 0.055 & 0.044 \\
\hline \multirow[t]{2}{*}{ Nagasaki } & 0.082 & 0.065 & 0.062 & 0.058 & 0.052 & 0.066 & 0.062 & 0.056 & 0.059 & 0.045 & 0.060 & 0.044 \\
\hline & \multicolumn{12}{|c|}{$\mathrm{r}-\mathrm{Cs}\left({ }^{134} \mathrm{Cs}+{ }^{137} \mathrm{Cs}\right)$} \\
\hline Region & Sep-2013 & Mar-2014 & Sep-2014 & Mar-2015 & Sep-2015 & Mar-2016 & Sep-2016 & Mar-2017 & Sep-2017 & Mar-2018 & Sep-2018 & Mar-2019 \\
\hline Fukushima (Hamadori) & 0.46 & 0.35 & 0.42 & 0.29 & 0.25 & 0.17 & 0.20 & 0.18 & 0.16 & 0.17 & 0.16 & 0.13 \\
\hline Fukushima (Nakadori) & 0.49 & 0.35 & 0.30 & 0.37 & 0.29 & 0.18 & 0.23 & 0.18 & 0.16 & 0.21 & 0.21 & 0.19 \\
\hline Fukushima (Aizu) & 0.33 & 0.31 & 0.20 & 0.19 & 0.17 & 0.18 & 0.17 & 0.16 & 0.16 & 0.13 & 0.19 & 0.15 \\
\hline Iwate & 0.38 & 0.32 & 0.21 & 0.19 & 0.17 & 0.19 & 0.18 & 0.15 & 0.22 & 0.14 & 0.12 & 0.14 \\
\hline Miyagi & 0.35 & 0.22 & 0.24 & 0.18 & 0.17 & 0.13 & 0.18 & 0.17 & 0.16 & 0.20 & 0.14 & 0.11 \\
\hline Tochigi & 0.29 & 0.23 & 0.23 & 0.17 & 0.17 & 0.20 & 0.26 & 0.19 & 0.14 & 0.14 & 0.19 & 0.16 \\
\hline Ibaraki & 0.27 & 0.21 & 0.22 & 0.16 & 0.21 & 0.14 & 0.20 & 0.15 & 0.13 & 0.16 & 0.13 & 0.094 \\
\hline Saitama & 0.23 & 0.16 & 0.25 & 0.16 & 0.21 & 0.13 & 0.15 & 0.16 & 0.12 & 0.11 & 0.11 & 0.13 \\
\hline Tokyo & 0.15 & 0.18 & 0.19 & 0.13 & 0.11 & 0.15 & 0.14 & 0.12 & 0.16 & 0.11 & 0.14 & 0.10 \\
\hline Kanagawa & 0.18 & 0.20 & 0.23 & 0.20 & 0.13 & 0.14 & 0.18 & 0.14 & 0.12 & 0.12 & 0.11 & 0.14 \\
\hline Niigata & 0.19 & 0.15 & 0.18 & 0.13 & 0.12 & 0.11 & 0.15 & 0.12 & 0.10 & 0.11 & 0.11 & 0.10 \\
\hline Hokkaido & 0.15 & 0.16 & 0.12 & 0.11 & 0.23 & 0.13 & 0.13 & 0.12 & 0.11 & 0.10 & 0.11 & 0.092 \\
\hline Osaka & 0.17 & 0.13 & 0.12 & 0.11 & 0.13 & 0.13 & 0.12 & 0.11 & 0.10 & 0.09 & 0.11 & 0.10 \\
\hline Kochi & 0.14 & 0.16 & 0.13 & 0.11 & 0.13 & 0.11 & 0.12 & 0.13 & 0.10 & 0.10 & 0.10 & 0.087 \\
\hline \multirow[t]{2}{*}{ Nagasaki } & 0.15 & 0.13 & 0.12 & 0.11 & 0.10 & 0.12 & 0.12 & 0.11 & 0.10 & 0.086 & 0.10 & 0.085 \\
\hline & \multicolumn{12}{|c|}{${ }^{40} \mathrm{~K}$} \\
\hline Region & Sep-2013 & Mar-2014 & Sep-2014 & Mar-2015 & Sep-2015 & Mar-2016 & Sep-2016 & Mar-2017 & Sep-2017 & Mar-2018 & Sep-2018 & Mar-2019 \\
\hline Fukushima (Hamadori) & 89 & 80 & 78 & 79 & 82 & 83 & 80 & 80 & 80 & 78 & 74 & 77 \\
\hline Fukushima (Nakadori) & 91 & 85 & 80 & 84 & 79 & 80 & 77 & 78 & 75 & 78 & 77 & 77 \\
\hline Fukushima (Aizu) & 84 & 85 & 85 & 78 & 77 & 84 & 80 & 81 & 78 & 76 & 76 & 76 \\
\hline Iwate & 91 & 83 & 84 & 79 & 78 & 82 & 78 & 79 & 79 & 81 & 74 & 80 \\
\hline Miyagi & 90 & 83 & 82 & 76 & 81 & 85 & 81 & 85 & 78 & 79 & 80 & 84 \\
\hline Tochigi & 78 & 76 & 76 & 75 & 73 & 75 & 80 & 79 & 81 & 78 & 80 & 76 \\
\hline Ibaraki & 79 & 80 & 72 & 71 & 72 & 78 & 77 & 78 & 78 & 77 & 77 & 80 \\
\hline Saitama & 77 & 74 & 75 & 69 & 69 & 70 & 77 & 80 & 79 & 76 & 75 & 76 \\
\hline Tokyo & 75 & 73 & 74 & 73 & 70 & 72 & 76 & 78 & 77 & 77 & 77 & 82 \\
\hline Kanagawa & 73 & 74 & 73 & 71 & 68 & 73 & 80 & 79 & 76 & 78 & 79 & 73 \\
\hline Niigata & 82 & 81 & 82 & 77 & 77 & 78 & 81 & 81 & 81 & 80 & 76 & 81 \\
\hline Hokkaido & 71 & 71 & 70 & 72 & 72 & 70 & 73 & 72 & 72 & 75 & 72 & 71 \\
\hline Osaka & 70 & 76 & 72 & 70 & 68 & 71 & 72 & 74 & 77 & 67 & 69 & 71 \\
\hline Kochi & 66 & 66 & 67 & 64 & 63 & 65 & 76 & 75 & 79 & 74 & 70 & 72 \\
\hline Nagasaki & 62 & 68 & 67 & 68 & 66 & 67 & 70 & 76 & 74 & 76 & 70 & 71 \\
\hline
\end{tabular}

These values were calculated using half of the LODs as concentrations of MB samples less than LODs. 


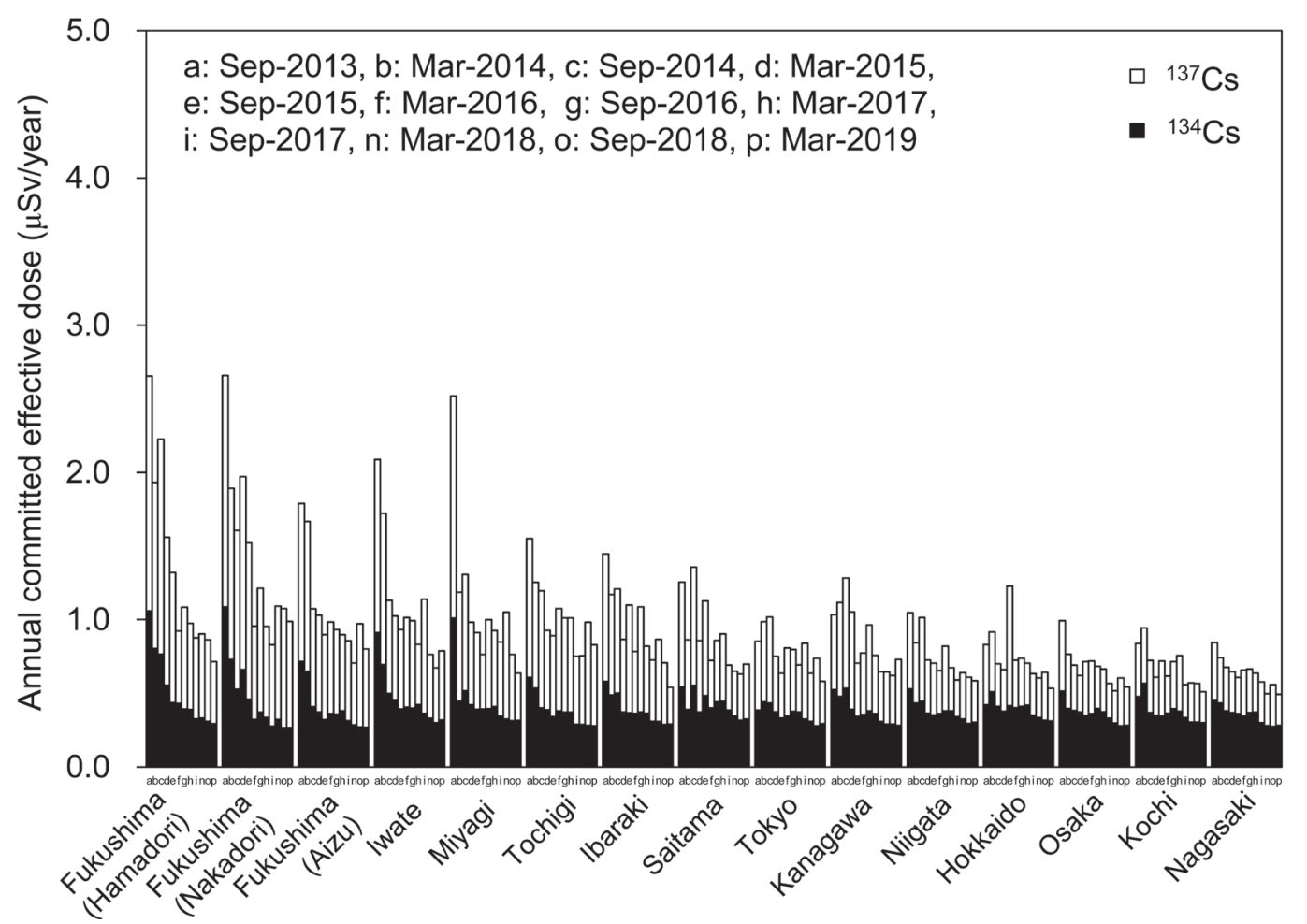

Fig. 6. Time trends of annual committed effective doses of ${ }^{134} \mathrm{Cs}$ and ${ }^{137} \mathrm{Cs}$ in each region. Filled column and opened column indicate the annual committed effective doses of ${ }^{134} \mathrm{Cs}$ and ${ }^{137} \mathrm{Cs}$, respectively. For each region, data are sorted according to the time of study.

ferences in daily intake and annual committed effective dose from ${ }^{134} \mathrm{Cs}$ in each year after Sep-2015 because ${ }^{134} \mathrm{Cs}$ was not detected in almost all MB samples. Daily intake and annual committed effective dose of ${ }^{134} \mathrm{Cs}$ in all regions slightly decreased in Sep-2017 and have since remained mostly stable, although the detection rate for ${ }^{134} \mathrm{Cs}$ was already near zero in all regions before Sep-2017. This was probably caused by the lower LODs related to changes in the measurement environment, as described in the Materials and Methods section. Assuming that ${ }^{134} \mathrm{Cs}$ is continuously not detected in any region in the future, it is expected that estimated daily intake and annual committed effective dose of ${ }^{134} \mathrm{Cs}$ will be at similar levels, approximately $0.04 \mathrm{~Bq} /$ day and $0.3 \mu \mathrm{Sv} /$ year, respectively, given their respective LODs which have been at similar levels since Sep-2017. On the other hand, daily intake and annual committed effective dose of ${ }^{137} \mathrm{Cs}$ in regions relatively close to the FDNPP such as Fukushima, Iwate, and Tochigi are still slightly higher than those in the far-FDNPP region. These results suggest that differences in daily intake and annual committed effective dose among regions were mainly attributed to ${ }^{137} \mathrm{Cs}$, which tended to decrease in the near-FDNPP region. Similarly, daily intake and annual committed effective dose of ${ }^{137} \mathrm{Cs}$ in the far-FDNPP region appeared to decrease slightly, however, it was difficult to describe the time trend of ${ }^{137} \mathrm{Cs}$ in these regions due to low detection rates and to changes in LOD during the study. Since detection rates for ${ }^{137} \mathrm{Cs}$ in the far-FDNPP region were quite low $(7 \sim 14 \%)$ and their concentrations were also low in Mar-2019, daily intake and annual committed effective dose of ${ }^{137} \mathrm{Cs}$ were close to their respective LOD values, which were approximately $0.04 \mathrm{~Bq} /$ day and $0.2 \mu \mathrm{Sv} / \mathrm{year}$. As expected, the amount of daily intake and annual committed effective dose of $\mathrm{r}-\mathrm{Cs}$ in the far-FDNPP region in our study were similar to the most recent values, approximately 0.08 $\mathrm{Bq} /$ day and $0.5 \mu \mathrm{Sv} / \mathrm{year}$, respectively, even if the detection rate for ${ }^{137} \mathrm{Cs}$ has become $0 \%$.

Regarding food categories, because r-Cs were not detected or their concentrations were at very low levels, food consumption mainly contributed to the daily intake of $\mathrm{r}-\mathrm{Cs}$ in the far-FDNPP region. Indeed, daily intake of r-Cs in category 9 , which had the highest consumption, was estimated to be the highest among 14 food categories. Since the detection rate for ${ }^{137} \mathrm{Cs}$ in categories $1,2,8,10$, and 12 was high in the nearFDNPP region, and food consumption of these categories was relatively high, daily intake of ${ }^{137} \mathrm{Cs}$ in the near-FDNPP region was higher for these categories than for category 9. On the other hand, although a relatively high concentration of ${ }^{137} \mathrm{Cs}$ was detected in category 5 in regions such as Iwate, 


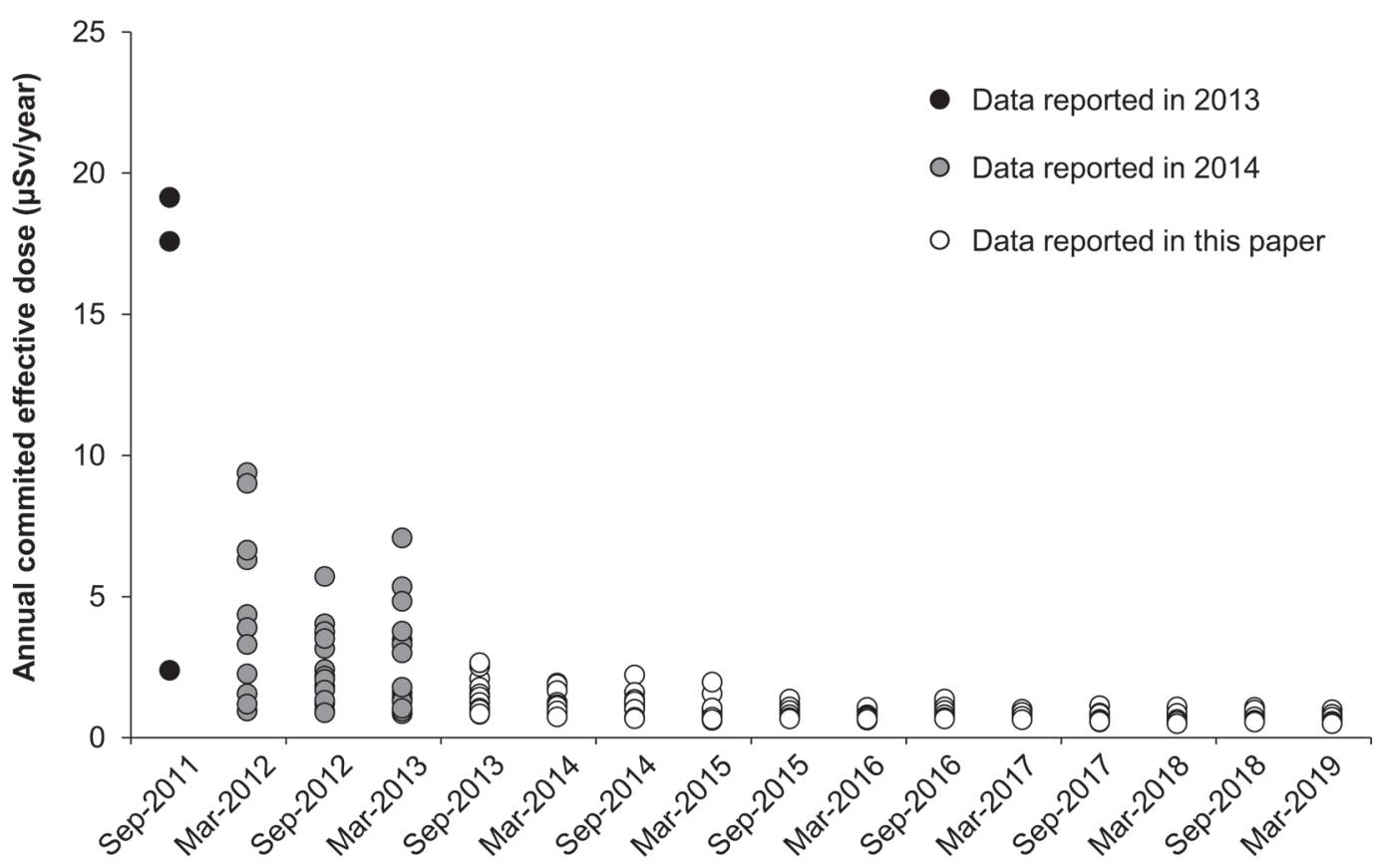

Fig. 7. Time trends of the ranges of annual committed effective dose of $\mathrm{r}$-Cs in this study and our previous reports. Filled circles and gray circles indicate previous data reported in 2013 and 2014, respectively. Opened circles indicate data in this study.

Fukushima (Hamadori), and Fukushima (Nakadori), daily intake of ${ }^{137} \mathrm{Cs}$ in this category was not high because the corresponding food consumption was low.

The ranges of annual committed effective dose of r-Cs among regions in this study were narrow compared with our previous study reported in 2013 ${ }^{17)}$ and 2014 ${ }^{18)}$ (Fig. 7). Compared with results before Mar-2013, the decreasing rate of annual committed effective dose of r-Cs during the 5.5year duration of the present study was slow and was likely related to (1) an attenuation of ${ }^{134} \mathrm{Cs}$ and ${ }^{137} \mathrm{Cs}$ by their physical half-lives, (2) a decrease of $\mathrm{r}$-Cs concentration in foods by production management, and (3) a decrease of r-Cs concentration in commercial domestic foods in Japan by the strict standard limit implemented in April 2012. We suggest that a drastic decrease in $\mathrm{r}$-Cs concentration by the effects of countermeasures such as (2) and (3) largely contributed to a remarkable decrease in annual committed effective dose before Mar-2013. Since Sep-2013, the decrease in r-Cs concentration in distributed foods was thought to be slow, not drastic. Indeed, according to a report that summarized monitoring data released by the Ministry of Health, Labour and Welfare of Japan ${ }^{26)}$, r-Cs concentration in leafy vegetables, beef, cultivated mushrooms, and fishery products remarkably decreased until around 2013, after which it has slowly decreased or remained substantially unchanged.

Daily intake of ${ }^{137} \mathrm{Cs}$ in Japan before the FDNPP accident was reported by Sugiyama et al in 200723). According to previous data, daily intake of ${ }^{137} \mathrm{Cs}$ in 13 cities in Japan (Sapporo, Sendai, Saitama, Chiba, Yokohama, Niigata, Nagoya, Osaka, Kobe, Yamaguchi, Takamatsu, Fukuoka, and Naha) ranged from 0.012 to $0.042 \mathrm{~Bq} /$ day (calculated from only quantifiable values, which means that ND was handled as 0 ) and $<0.038$ to $<0.080 \mathrm{~Bq} / \mathrm{day}$ (calculated by assuming that concentrations less than the LODs were equal to the LODs, which means that ND was handled as the LOD), respectively. If these data were calculated by the present method (ND handled as half of the LOD), the daily intake of ${ }^{137} \mathrm{Cs}$ would range from 0.027 to $0.055 \mathrm{~Bq} / \mathrm{day}$. Another study of daily intake of ${ }^{137} \mathrm{Cs}$ by a food-duplicate survey was reported in the "environmental radiation database" by the nuclear regulatory agency of Japan ${ }^{27)}$. According to this database, daily intake of ${ }^{137} \mathrm{Cs}$ excluding non-detectable data for the periods between 1999 and 2008 (the latest decade before the FDNPP accident) ranged from 0.0071 to $0.56 \mathrm{~Bq} /$ day. Since food-duplicate surveys appear to be affected by individual differences in food consumption habits, the range of daily ${ }^{137} \mathrm{Cs}$ intake in that survey was considered to be large; median and 95th percentile were 0.028 and $0.063 \mathrm{~Bq} /$ day, respectively. On the other hand, the present results for daily ${ }^{137} \mathrm{Cs}$ intake in Mar-2019 ranged from 0.052 to $0.15 \mathrm{~Bq} /$ day in the near-FDNPP region and from 0.044 to $0.060 \mathrm{~Bq} /$ day in the far-FDNPP region. Although a direct comparison of these results should be done cautiously because of differences in factors such as LODs in the analytical methods and 
Table 3. Annual committed effective doses ( $\mu \mathrm{Sv} /$ year) of ${ }^{134} \mathrm{Cs},{ }^{137} \mathrm{Cs}, \mathrm{r}-\mathrm{Cs}$, and ${ }^{40} \mathrm{~K}$ in 15 regions

\begin{tabular}{|c|c|c|c|c|c|c|c|c|c|c|c|c|}
\hline \multirow{2}{*}{ Region } & \multicolumn{12}{|c|}{${ }^{134} \mathrm{Cs}$} \\
\hline & Sep-2013 & Mar-2014 & Sep-2014 & Mar-2015 & Sep-2015 & Mar-2016 & Sep-2016 & Mar-2017 & Sep-2017 & Mar-2018 & Sep-2018 & Mar-2019 \\
\hline Fukushima (Hamadori) & 1.1 & 0.80 & 0.77 & 0.56 & 0.44 & 0.43 & 0.39 & 0.39 & 0.33 & 0.33 & 0.31 & 0.29 \\
\hline Fukushima (Nakadori) & 1.1 & 0.73 & 0.53 & 0.66 & 0.46 & 0.32 & 0.37 & 0.34 & 0.28 & 0.32 & 0.26 & 0.27 \\
\hline Fukushima (Aizu) & 0.72 & 0.65 & 0.41 & 0.37 & 0.32 & 0.36 & 0.36 & 0.38 & 0.31 & 0.29 & 0.27 & 0.27 \\
\hline Iwate & 0.91 & 0.69 & 0.50 & 0.46 & 0.39 & 0.41 & 0.40 & 0.42 & 0.36 & 0.33 & 0.30 & 0.32 \\
\hline Miyagi & 1.0 & 0.45 & 0.52 & 0.42 & 0.39 & 0.39 & 0.39 & 0.41 & 0.35 & 0.32 & 0.31 & 0.31 \\
\hline Tochigi & 0.61 & 0.53 & 0.40 & 0.39 & 0.34 & 0.38 & 0.45 & 0.37 & 0.29 & 0.29 & 0.28 & 0.28 \\
\hline Tbaraki & 0.58 & 0.49 & 0.50 & 0.37 & 0.37 & 0.36 & 0.37 & 0.37 & 0.31 & 0.31 & 0.29 & 0.29 \\
\hline Saitama & 0.54 & 0.39 & 0.55 & 0.37 & 0.48 & 0.40 & 0.44 & 0.45 & 0.39 & 0.35 & 0.32 & 0.32 \\
\hline Tokyo & 0.39 & 0.44 & 0.43 & 0.37 & 0.33 & 0.35 & 0.38 & 0.37 & 0.32 & 0.31 & 0.28 & 0.29 \\
\hline Kanagawa & 0.52 & 0.48 & 0.53 & 0.39 & 0.34 & 0.36 & 0.38 & 0.36 & 0.31 & 0.29 & 0.29 & 0.28 \\
\hline Niigata & 0.53 & 0.43 & 0.45 & 0.37 & 0.35 & 0.36 & 0.38 & 0.38 & 0.34 & 0.33 & 0.30 & 0.30 \\
\hline Hokkaido & 0.42 & 0.51 & 0.41 & 0.38 & 0.42 & 0.40 & 0.41 & 0.42 & 0.35 & 0.33 & 0.32 & 0.31 \\
\hline Osaka & 0.51 & 0.40 & 0.38 & 0.37 & 0.35 & 0.36 & 0.40 & 0.37 & 0.33 & 0.30 & 0.28 & 0.28 \\
\hline Kochi & 0.48 & 0.57 & 0.37 & 0.35 & 0.35 & 0.36 & 0.40 & 0.38 & 0.33 & 0.30 & 0.30 & 0.30 \\
\hline \multirow[t]{2}{*}{ Nagasaki } & 0.46 & 0.43 & 0.38 & 0.37 & 0.36 & 0.35 & 0.37 & 0.37 & 0.30 & 0.28 & 0.27 & 0.28 \\
\hline & \multicolumn{12}{|c|}{${ }^{137} \mathrm{Cs}$} \\
\hline Region & Sep-2013 & Mar-2014 & Sep-2014 & Mar-2015 & Sep-2015 & Mar-2016 & Sep-2016 & Mar-2017 & Sep-2017 & Mar-2018 & Sep-2018 & Mar-2019 \\
\hline Fukushima (Hamadori) & 1.6 & 1.1 & 1.5 & 1.0 & 0.88 & 0.49 & 0.69 & 0.59 & 0.55 & 0.57 & 0.55 & 0.42 \\
\hline Fukushima (Nakadori) & 1.6 & 1.2 & 1.1 & 1.3 & 1.1 & 0.63 & 0.84 & 0.62 & 0.55 & 0.77 & 0.81 & 0.72 \\
\hline Fukushima (Aizu) & 1.1 & 1.0 & 0.67 & 0.66 & 0.58 & 0.62 & 0.57 & 0.52 & 0.54 & 0.42 & 0.70 & 0.53 \\
\hline Iwate & 1.2 & 1.0 & 0.63 & 0.57 & 0.54 & 0.61 & 0.59 & 0.41 & 0.78 & 0.43 & 0.37 & 0.47 \\
\hline Miyagi & 1.5 & 0.74 & 0.79 & 0.56 & 0.52 & 0.37 & 0.60 & 0.51 & 0.50 & 0.73 & 0.45 & 0.32 \\
\hline Tochigi & 0.94 & 0.72 & 0.80 & 0.54 & 0.55 & 0.69 & 0.92 & 0.64 & 0.46 & 0.47 & 0.70 & 0.55 \\
\hline Ibaraki & 0.87 & 0.68 & 0.71 & 0.49 & 0.73 & 0.42 & 0.71 & 0.45 & 0.42 & 0.56 & 0.42 & 0.25 \\
\hline Saitama & 0.71 & 0.47 & 0.80 & 0.48 & 0.64 & 0.32 & 0.42 & 0.46 & 0.30 & 0.30 & 0.31 & 0.37 \\
\hline Tokyo & 0.47 & 0.54 & 0.58 & 0.38 & 0.30 & 0.46 & 0.42 & 0.32 & 0.51 & 0.33 & 0.46 & 0.29 \\
\hline Kanagawa & 0.51 & 0.64 & 0.75 & 0.66 & 0.36 & 0.42 & 0.58 & 0.40 & 0.34 & 0.35 & 0.33 & 0.45 \\
\hline Niigata & 0.52 & 0.41 & 0.57 & 0.36 & 0.35 & 0.29 & 0.44 & 0.29 & 0.25 & 0.31 & 0.31 & 0.28 \\
\hline Hokkaido & 0.41 & 0.40 & 0.29 & 0.28 & 0.81 & 0.32 & 0.33 & 0.29 & 0.28 & 0.27 & 0.33 & 0.22 \\
\hline Osaka & 0.48 & 0.37 & 0.31 & 0.25 & 0.36 & 0.36 & 0.29 & 0.29 & 0.24 & 0.22 & 0.32 & 0.26 \\
\hline Kochi & 0.36 & 0.38 & 0.35 & 0.26 & 0.37 & 0.25 & 0.32 & 0.38 & 0.22 & 0.27 & 0.26 & 0.21 \\
\hline \multirow[t]{2}{*}{ Nagasaki } & 0.39 & 0.31 & 0.29 & 0.28 & 0.25 & 0.31 & 0.30 & 0.27 & 0.28 & 0.22 & 0.28 & 0.21 \\
\hline & \multicolumn{12}{|c|}{$\mathrm{r}-\mathrm{Cs}\left({ }^{134} \mathrm{Cs}+{ }^{137} \mathrm{Cs}\right)$} \\
\hline Region & Sep-2013 & Mar-2014 & Sep-2014 & Mar-2015 & Sep-2015 & Mar-2016 & Sep-2016 & Mar-2017 & Sep-2017 & Mar-2018 & Sep-2018 & Mar-2019 \\
\hline Fukushima (Hamadori) & 2.7 & 1.9 & 2.2 & 1.6 & 1.3 & 0.92 & 1.1 & 0.98 & 0.88 & 0.90 & 0.86 & 0.71 \\
\hline Fukushima (Nakadori) & 2.7 & 1.9 & 1.6 & 2.0 & 1.5 & 0.96 & 1.2 & 0.95 & 0.83 & 1.1 & 1.1 & 0.99 \\
\hline Fukushima (Aizu) & 1.8 & 1.7 & 1.1 & 1.0 & 0.90 & 0.98 & 0.93 & 0.90 & 0.86 & 0.71 & 0.97 & 0.80 \\
\hline Iwate & 2.1 & 1.7 & 1.1 & 1.0 & 0.93 & 1.0 & 0.99 & 0.83 & 1.1 & 0.76 & 0.67 & 0.79 \\
\hline Miyagi & 2.5 & 1.2 & 1.3 & 0.98 & 0.91 & 0.76 & 1.0 & 0.92 & 0.85 & 1.1 & 0.76 & 0.64 \\
\hline Tochigi & 1.5 & 1.3 & 1.2 & 0.93 & 0.89 & 1.1 & 1.4 & 1.0 & 0.75 & 0.75 & 0.98 & 0.83 \\
\hline Ibaraki & 1.4 & 1.2 & 1.2 & 0.87 & 1.1 & 0.78 & 1.1 & 0.82 & 0.73 & 0.86 & 0.71 & 0.54 \\
\hline Saitama & 1.3 & 0.86 & 1.4 & 0.86 & 1.1 & 0.72 & 0.86 & 0.90 & 0.69 & 0.65 & 0.63 & 0.70 \\
\hline Tokyo & 0.85 & 0.99 & 1.0 & 0.75 & 0.64 & 0.81 & 0.80 & 0.69 & 0.84 & 0.64 & 0.74 & 0.58 \\
\hline Kanagawa & 1.0 & 1.1 & 1.3 & 1.1 & 0.70 & 0.77 & 0.96 & 0.76 & 0.65 & 0.64 & 0.62 & 0.73 \\
\hline Niigata & 1.0 & 0.84 & 1.0 & 0.73 & 0.70 & 0.65 & 0.82 & 0.67 & 0.59 & 0.64 & 0.61 & 0.59 \\
\hline Hokkaido & 0.83 & 0.91 & 0.70 & 0.66 & 1.2 & 0.72 & 0.74 & 0.70 & 0.63 & 0.60 & 0.64 & 0.53 \\
\hline Osaka & 0.99 & 0.76 & 0.69 & 0.62 & 0.71 & 0.72 & 0.68 & 0.66 & 0.57 & 0.52 & 0.60 & 0.54 \\
\hline Kochi & 0.84 & 0.94 & 0.72 & 0.61 & 0.72 & 0.62 & 0.71 & 0.75 & 0.56 & 0.57 & 0.57 & 0.51 \\
\hline \multirow[t]{2}{*}{ Nagasaki } & 0.84 & 0.74 & 0.68 & 0.65 & 0.61 & 0.66 & 0.66 & 0.64 & 0.58 & 0.50 & 0.56 & 0.49 \\
\hline & \multicolumn{12}{|c|}{${ }^{40} \mathrm{~K}$} \\
\hline Region & Sep-2013 & Mar-2014 & Sep-2014 & Mar-2015 & Sep-2015 & Mar-2016 & Sep-2016 & Mar-2017 & Sep-2017 & Mar-2018 & Sep-2018 & Mar-2019 \\
\hline Fukushima (Hamadori) & 200 & 180 & 180 & 180 & 190 & 190 & 180 & 180 & 180 & 180 & 170 & 170 \\
\hline Fukushima (Nakadori) & 210 & 190 & 180 & 190 & 180 & 180 & 170 & 180 & 170 & 180 & 170 & 170 \\
\hline Fukushima (Aizu) & 190 & 190 & 190 & 180 & 170 & 190 & 180 & 180 & 180 & 170 & 170 & 170 \\
\hline Iwate & 210 & 190 & 190 & 180 & 180 & 190 & 180 & 180 & 180 & 180 & 170 & 180 \\
\hline Miyagi & 200 & 190 & 190 & 170 & 180 & 190 & 180 & 190 & 180 & 180 & 180 & 190 \\
\hline Tochigi & 180 & 170 & 170 & 170 & 170 & 170 & 180 & 180 & 180 & 180 & 180 & 170 \\
\hline Ibaraki & 180 & 180 & 180 & 160 & 160 & 180 & 170 & 180 & 180 & 170 & 170 & 180 \\
\hline Saitama & 170 & 170 & 170 & 160 & 160 & 160 & 170 & 180 & 180 & 170 & 170 & 170 \\
\hline Tokyo & 170 & 170 & 170 & 170 & 160 & 160 & 170 & 180 & 170 & 170 & 170 & 190 \\
\hline Kanagawa & 170 & 170 & 160 & 160 & 150 & 170 & 180 & 180 & 170 & 180 & 180 & 170 \\
\hline Niigata & 180 & 180 & 190 & 180 & 170 & 180 & 180 & 180 & 180 & 180 & 170 & 180 \\
\hline Hokkaido & 160 & 160 & 160 & 160 & 160 & 160 & 170 & 160 & 160 & 170 & 160 & 160 \\
\hline Osaka & 160 & 170 & 160 & 160 & 150 & 160 & 160 & 170 & 170 & 150 & 160 & 160 \\
\hline Kochi & 150 & 150 & 150 & 150 & 140 & 150 & 170 & 170 & 180 & 170 & 160 & 160 \\
\hline Nagasaki & 140 & 150 & 150 & 150 & 150 & 150 & 160 & 170 & 170 & 170 & 160 & 160 \\
\hline
\end{tabular}

These values were calculated using half of the LODs as concentrations of MB samples less than LODs. 
Table 4. The ranges of daily intake (A) and annual committed effective dose (B) of radionuclides in each period

\begin{tabular}{|c|c|c|c|c|c|c|c|c|c|c|c|c|}
\hline \multirow{2}{*}{ Radionuclodes } & \multicolumn{12}{|c|}{ The ranges of daily intake of radionuclides $(\mathrm{Bq} /$ day $)$} \\
\hline & Sep-2013 & Mar-2014 & Sep-2014 & Mar-2015 & Sep-2015 & Mar-2016 & Sep-2016 & Mar-2017 & Sep-2017 & Mar-2018 & Sep-2018 & Mar-2019 \\
\hline \multirow{2}{*}{${ }^{134} \mathrm{Cs}$} & $0.056-0.16$ & $0.056-0.12$ & $0.053-0.11$ & $0.050-0.10$ & $0.046-0.070$ & $0.046-0.062$ & $0.052-0.065$ & $0.048-0.064$ & $0.040-0.056$ & $0.040-0.050$ & $0.038-0.046$ & $0.039-0.047$ \\
\hline & $(0-0.12)$ & $(0-0.082)$ & $(0-0.073)$ & $(0-0.055)$ & $(0-0.020)$ & $(0-0.010)$ & $(0-0.019)$ & $(0-0.0088)$ & $(0-0.0061)$ & $(0-0.0091)$ & $(0-0)$ & $(0-0)$ \\
\hline \multirow{2}{*}{${ }^{137} \mathrm{Cs}$} & $0.076-0.34$ & $0.065-0.24$ & $0.061-0.31$ & $0.052-0.28$ & $0.052-0.22$ & $0.053-0.15$ & $0.060-0.19$ & $0.056-0.14$ & $0.047-0.16$ & $0.045-0.16$ & $0.055-0.17$ & $0.044-0.15$ \\
\hline & $(0.017-0.31)$ & $(0.0091-0.22)$ & $(0.011-0.29)$ & $(0.0052-0.25)$ & $(0.0057-0.20)$ & $(0.0075-0.11)$ & $(0.014-0.15)$ & $(0.0060-0.11)$ & $(0.0051-0.14)$ & $(0.0049-0.14)$ & $(0.018-0.15)$ & $(0.0045-0.14)$ \\
\hline \multirow{2}{*}{$\mathrm{r}-\mathrm{Cs}\left({ }^{134} \mathrm{Cs}+{ }^{137} \mathrm{Cs}\right)$} & $0.15-0.49$ & $0.13-0.35$ & $0.12-0.42$ & $0.11-0.37$ & $0.10-0.29$ & $0.11-0.20$ & $0.12-0.26$ & $0.11-0.19$ & $0.096-0.22$ & $0.086-0.21$ & $0.099-0.21$ & $0.085-0.19$ \\
\hline & $(0.017-0.44)$ & $(0.0091-0.30)$ & $(0.011-0.36)$ & $(0.0052-0.30)$ & $(0.0057-0.23)$ & $(0.0075-0.12)$ & $(0.015-0.16)$ & $(0.0060-0.11)$ & $(0.0051-0.14)$ & $(0.0049-0.15)$ & $(0.018-0.15)$ & $(0.0045-0.14)$ \\
\hline \multirow{2}{*}{${ }^{40} \mathrm{~K}$} & $62-91$ & $66-85$ & $67-85$ & $64-84$ & $63-82$ & $65-85$ & $70-81$ & $72-85$ & $72-81$ & $67-81$ & $69-80$ & $71-84$ \\
\hline & $(62-91)$ & $(65-85)$ & $(67-85)$ & $(64-84)$ & $(62-82)$ & $(65-85)$ & $(70-81)$ & $(72-85)$ & $(72-81)$ & $(67-80)$ & $(69-80)$ & $(71-84)$ \\
\hline
\end{tabular}

B.

\begin{tabular}{|c|c|c|c|c|c|c|c|c|c|c|c|c|}
\hline \multirow{2}{*}{ Radionuclodes } & \multicolumn{12}{|c|}{ The ranges of annual committed effective dose of radionuclides ( $\mu \mathrm{Sv} /$ year) } \\
\hline & Sep-2013 & Mar-2014 & Sep-2014 & Mar-2015 & Sep-2015 & Mar-2016 & Sep-2016 & Mar-2017 & Sep-2017 & Mar-2018 & Sep-2018 & Mar-2019 \\
\hline \multirow{2}{*}{${ }^{134} \mathrm{Cs}$} & $0.39-1.1$ & $0.39-0.80$ & $0.37-0.77$ & $0.35-0.66$ & $0.32-0.48$ & $0.32-0.43$ & $0.36-0.45$ & $0.34-0.45$ & $0.28-0.39$ & $0.28-0.35$ & $0.26-0.32$ & $0.27-0.32$ \\
\hline & $(0-0.85)$ & $(0-0.57)$ & $(0-0.51)$ & $(0-0.38)$ & $(0-0.14)$ & $(0-0.071)$ & $(0-0.13)$ & $(0-0.060)$ & $(0-0.042)$ & $(0-0.063)$ & $(0-0)$ & $(0-0)$ \\
\hline \multirow{2}{*}{${ }^{137} \mathrm{Cs}$} & $0.36-1.6$ & $0.31-1.2$ & $0.29-1.5$ & $0.25-1.3$ & $0.25-1.1$ & $0.25-0.69$ & $0.29-0.92$ & $0.27-0.64$ & $0.22-0.78$ & $0.22-0.77$ & $0.26-0.81$ & $0.21-0.72$ \\
\hline & $(0.079-1.5)$ & $(0.043-1.0)$ & $(0.051-1.4)$ & $(0.025-1.2)$ & $(0.027-0.97)$ & $(0.036-0.56)$ & $(0.064-0.78)$ & $(0.029-0.53)$ & $(0.024-0.67)$ & $(0.023-0.65)$ & $(0.087-0.72)$ & $(0.021-0.68)$ \\
\hline \multirow{2}{*}{$\mathrm{r}-\mathrm{Cs}\left({ }^{134} \mathrm{Cs}+{ }^{137} \mathrm{Cs}\right)$} & $0.83-2.7$ & $0.74-1.9$ & $0.68-2.2$ & $0.61-2.0$ & $0.61-1.5$ & $0.62-1.1$ & $0.66-1.4$ & $0.64-1.0$ & $0.56-1.1$ & $0.50-1.1$ & $0.65-1.1$ & $0.49-1.0$ \\
\hline & $(0.079-2.3)$ & $(0.043-1.6)$ & $(0.051-1.9)$ & $(0.025-1.5)$ & $(0.027-1.1)$ & $(0.036-0.60)$ & $(0.075-0.92)$ & $(0.029-0.53)$ & $(0.024-0.67)$ & $(0.023-0.65)$ & $(0.087-0.72)$ & $(0.021-0.68)$ \\
\hline \multirow{2}{*}{${ }^{40} \mathrm{~K}$} & $140-210$ & $150-190$ & $150-190$ & $150-190$ & $140-190$ & $150-190$ & $160-180$ & $160-190$ & $160-180$ & $150-180$ & $160-180$ & $160-190$ \\
\hline & $(140-210)$ & $(150-190)$ & $(150-190)$ & $(150-190)$ & $(140-180)$ & $(150-190)$ & $(160-180)$ & $(160-190)$ & $(160-180)$ & $(150-180)$ & $(160-180)$ & $(160-190)$ \\
\hline
\end{tabular}

These values were calculated using half of the LODs as concentrations of MB samples less than LODs.

Shown in parentheses are the values calculated from only the quantifiable values, that means that ND were handled as 0.

ND assumptions, the most recent daily ${ }^{137} \mathrm{Cs}$ intake in the far-FDNPP region was very close to or below the upper limits before the accident. On the other hand, the most recent daily ${ }^{137} \mathrm{Cs}$ intake in parts of the near-FNDPP region was about two times higher than the upper limits before the accident. However, the maximum annual committed effective dose of r-Cs estimated by our most recent study in March 2019 was $1.0 \mu \mathrm{Sv} / \mathrm{year}$, which corresponds to approximately $0.1 \%$ of the intervention exemption level ( $1 \mathrm{mSv} / \mathrm{year})$, a value sufficiently lower than the intervention exemption level. This finding suggested that $\mathrm{r}$-Cs in commercial foods have been well-controlled in Japan.

On the other hand, daily intake and annual committed effective dose of ${ }^{40} \mathrm{~K}$ ranged from approximately 60 to $90 \mathrm{~Bq} /$ day and 150 to $200 \mu \mathrm{Sv} / \mathrm{year}$, respectively (Tables 2 and 3), values that did not change much regardless of the time periods and regions. As an additional comparison, the dose received from ${ }^{40} \mathrm{~K}$ is estimated to be $165 \mu \mathrm{Sv} /$ year for adults, which is held fairly constant due to homeostasis ${ }^{28}$. Compared with the maximum annual committed effective dose of r-Cs estimated in the present study, the maximum annual committed effective dose of ${ }^{40} \mathrm{~K}$ was approximately 75 -fold higher. Furthermore, the annual committed effective dose of $\mathrm{r}$-Cs was sufficiently lower than that for ${ }^{40} \mathrm{~K}$ (less than $2 \%$ ) and was within the range of variance. This result indicated that humans usually intake the natural radionuclide, ${ }^{40} \mathrm{~K}$, much more readily than they intake r-Cs.

We conclude that estimated daily intake and annual committed effective dose of $\mathrm{r}$-Cs during the periods from Sep-2013 to Mar-2019 appeared to decrease gradually in the near-FDNPP region, and estimated annual committed effective doses of $\mathrm{r}$-Cs were much lower than the intervention exemption level $(1 \mathrm{mSv} / \mathrm{year})$ in all regions and time periods. These results demonstrate that the health risk of ingestion $\mathrm{r}-\mathrm{Cs}$ is significantly low when consuming normal diets that include commercial foods on the Japanese market. Nevertheless, to ensure food safety from the viewpoint of risk communication, it would be necessary to continue to monitor and disclose the daily intake and annual committed effective dose of r-Cs.

\section{Acknowledgments}

This study was supported by the Ministry of Health, Labour and Welfare of Japan. We thank Satoshi Takatsuki and Tomomi Maeda for their assistance in the $\gamma$-ray measurements of MB samples.

\section{Conflict of Interest}

The authors declare that they have no conflict of interest.

\section{Source of funding}

This study was supported by the Ministry of Health, Labour and Welfare of Japan. 


\section{References}

1. Ministry of Economy, Trade and Industry. Report of evaluation of reactor core state in Unit 1,2 and 3 concerning the Tokyo Electric Power Company Fukushima Daiichi Nuclear Power Plant accident [in Japanese]. https://warp.da.ndl.go.jp/ info:ndljp/pid/3491887/www.meti.go.jp/earthquake/nuclear/ pdf/20110606-1nisa.pdf. Published June 6, 2011. Accessed May 21, 2020.

2. Japan Radioisotope Association. Radioisotope Pocket Data Book. 11th ed. [in Japanese] Bunkyo, Tokyo: Japan Rasioisotope Association; 2011:22-100. (ISBN 978-4-89073-211-1).

3. Ministry of Health Labour and Welfare. Handling of foods contaminated by radioactivity [in Japanese]. https://www.mhlw.go.jp/stf/houdou/2r9852000001558eimg/2r9852000001559v.pdf. Accessed May 21, 2020.

4. Ministry of Health Labour and Welfare. Summary of standard values of radioactive materials in foods [in Japanese]. http://www.mhlw.go.jp/shinsai_jouhou/dl/20130417-1.pdf Accessed May 21, 2020.

5. Nabeshi H, Tsutsumi T, Hachisuka A, Matsuda R. Variation in amount of radioactive cesium before and after cooking dry shiitake and beef [in Japanese]. Shokuhin Eiseigaku Zasshi. 2013; 54(1): 65-70. PMID:23470875, doi:10.3358/shokueishi. 54.65

6. Burger J, Gaines KF, Boring CS, Snodgrass J, Stephens WL Jr, Gochfeld M. Effects of cooking on radiocesium in fish from the Savannah River: exposure differences for the public. Arch Environ Contam Toxicol. 2004; 46(2): 231-235. PMID:15106675, doi:10.1007/s00244-003-2314-4

7. Nabeshi H, Tsutsumi T, Hachisuka A, Matsuda R. Reduction of radioactive cesium content in beef by soaking in seasoning [in Japanese]. Shokuhin Eiseigaku Zasshi. 2013; 54(4): 298-302. PMID:24025208, doi:10.3358/shokueishi.54.298

8. Nabeshi H, Tsutsumi T, Hachisuka A, Matsuda R. Reduction of radioactive cesium content in pond smelt by cooking [in Japanese]. Shokuhin Eiseigaku Zasshi. 2013; 54(4): 303-308. PMID:24025209, doi:10.3358/shokueishi.54.303

9. Nabeshi H, Tsutsumi T, Uekusa Y, et al. Changes in concentrations and amount of radioactive cesium in beef, wild vegetables and fruits by cooking. Radioisotopes. 2016; 65: 45-58. doi:10.3769/radioisotopes.65.45

10. Harada KH, Fujii Y, Adachi A, Tsukidate A, Asai F, Koizumi A. Dietary intake of radiocesium in adult residents in Fukushima prefecture and neighboring regions after the $\mathrm{Fu}-$ kushima nuclear power plant accident: 24-h food-duplicate survey in December 2011. Environ Sci Technol. 2013; 47(6): 2520-2526. PMID:23259847, doi:10.1021/es304128t

11. Sato O, Nonaka S, Tada JI. Intake of radioactive materials as assessed by the duplicate diet method in Fukushima. $J$ Radiol Prot. 2013; 33(4): 823-838. PMID:24080864, doi:10.1088/0952-4746/33/4/823

12. Ichihashi D, Aoyanagi N, Sato C, Uchino E, Itoh Y, Katsura E. Radioactive cesium in total diet in Hokkaido (2011-2012) [in Japanese]. Shokuhin Eiseigaku Zasshi. 2013; 54(2): 117120. PMID:23676690, doi:10.3358/shokueishi.54.117
13. Miyazaki H, Kato H, Kato Y, Tsuchiyama T, Terada H. Estimation of the intake of radioactive cesium based on analysis of total diet samples in Nagoya [in Japanese]. Shokuhin Eiseigaku Zasshi. 2013; 54(2): 151-155. PMID:23676694, doi:10.3358/shokueishi.54.151

14. Hirokawa D, Omori S, Nishimura N, Yoshida K, Wada I, Yamakoshi A. Survey of radioactive cesium and potassium intake from food using duplicate diet (Fiscal years 2011-2014) [in Japanese]. Shokuhin Eiseigaku Zasshi. 2016; 57(1): 7-12. PMID:26936303, doi:10.3358/shokueishi.57.7

15. Murakami M, Oki T. Estimated dietary intake of radionuclides and health risks for the citizens of Fukushima City, Tokyo, and Osaka after the 2011 nuclear accident. PLoS ONE. 2014; 9(11): e112791. PMID:25390339, doi:10.1371/journal. pone. 0112791

16. Takizawa M, Yoshizawa N, Kawai M, et al. Consideration of the estimations of the internal dose from food after the Fukushima Daiichi Nuclear Power Plant disaster. Journal of Japan Society for Safety Engineering. 2016; 55(1): 26-33.

17. Tsutsumi T, Nabeshi H, Ikarashi A, Hachisuka A, Matsuda R. Estimation of the committed effective dose of radioactive cesium and potassium by the market basket method [in Japanese]. Shokuhin Eiseigaku Zasshi. 2013; 54(1): 7-13. PMID:23470869, doi:10.3358/shokueishi.54.7

18. Uekusa Y, Nabeshi H, Tsutsumi T, Hachisuka A, Matsuda R, Teshima R. Estimation of dietary intake of radioactive materials by total diet methods [in Japanese]. Shokuhin Eiseigaku Zasshi. 2014; 55(4): 177-182. PMID:25212819, doi:10.3358/ shokueishi.55.177

19. Tsutsumi T, Matsuda R, Yanagi T, et al. Dietary intake of dioxins in Japan in 2016 with time trends since 1998. Food Addit Contam Part A Chem Anal Control Expo Risk Assess. 2018; 35(8): 1553-1564. PMID:29843576, doi:10.1080/19440 049.2018 .1469052

20. Ministry of Education Culture, Sports, Science and Technology. Gamma-ray Spectrometry using germanium detector, Radioactivity measurement series No.7 [in Japanese]. 1992, Tokyo, Japan Chemical Analysis Center. https:/www. kankyo-hoshano.go.jp/series/lib/No7.pdf. Accessed May 21, 2020.

21. GEMS/Food-EURO Second Workshop on Reliable Evaluation of Low-Level Contamination of Food Report on a Workshop in the Frame of GEMS / Food-EURO. Kulmbach, Germany, 26-27 May 1995 https://www.semanticscholar.org/ paper/GEMS-\%2F-Food-EURO-Second-Workshop-on-Reliable-of-of/7d5162794a407ce3361458649750a63b6bda3381 Accessed May 21, 2020.

22. ICRP Age-dependent Doses to the Members of the Public from Intake of Radionuclides - Part 5 Compilation of Ingestion and Inhalation Coefficients. ICRP Publication 72. 1995; 26(1). ISSN 0146-6453.

23. Sugiyama H, Terada H, Takahashi M, Iijima I, Isomura K. Contents and daily intakes of gamma-ray emitting nuclides, 90Sr, and $238 \mathrm{U}$ using market-basket studies in Japan. Journal of Health Science. 2007; 53(1): 107-118. doi:10.1248/ jhs. 53.107

24. Sasaki K, Hayashi M, Narita T, et al. Radiocesium distribution in the tissues of Japanese Black beef heifers fed falloutcontaminated roughage due to the Fukushima Daiichi Nuclear Power Station accident. Biosci Biotechnol Biochem. 2012; 76(8): 1596-1599. PMID:22878206, doi:10.1271/bbb.120424 
25. Ministry of Health, Labour and Welfare. Establishment of the management target level on radioactive materials in tap water [in Japanese]. https://www.mhlw.go.jp/stf/ houdou/2r98520000018ndf-att/2r98520000024of2.pdf. Accessed May 15, 2020.

26. Terada H, Yamaguchi I, Shimura T, Svendsen RE, Kunugita N. Regulation values and current situation of radioactive materials in foods. Journal of the National Institute of Public Health. 2018; 67(1): 21-33.
27. Nuclear Regulation Authority. Environmental radiation database [in Japanese]. https://search.kankyo-hoshano.go.jp/servlet/search.top Accessed May 6, 2020.

28. UNSCEAR. Sources and effects of ionizing radiation. UNSCEAR 2000 Report to the general assembly, with scientific annexes. Volume 1, AnnexX B Exposures from natural radiation sources. 2000; 84-141. https://www.unscear.org/docs/ publications/2000/UNSCEAR_2000_Annex-B.pdf. Accessed September 30, 2020 


\section{Supplementary materials}

Legends to Supplementary Figures

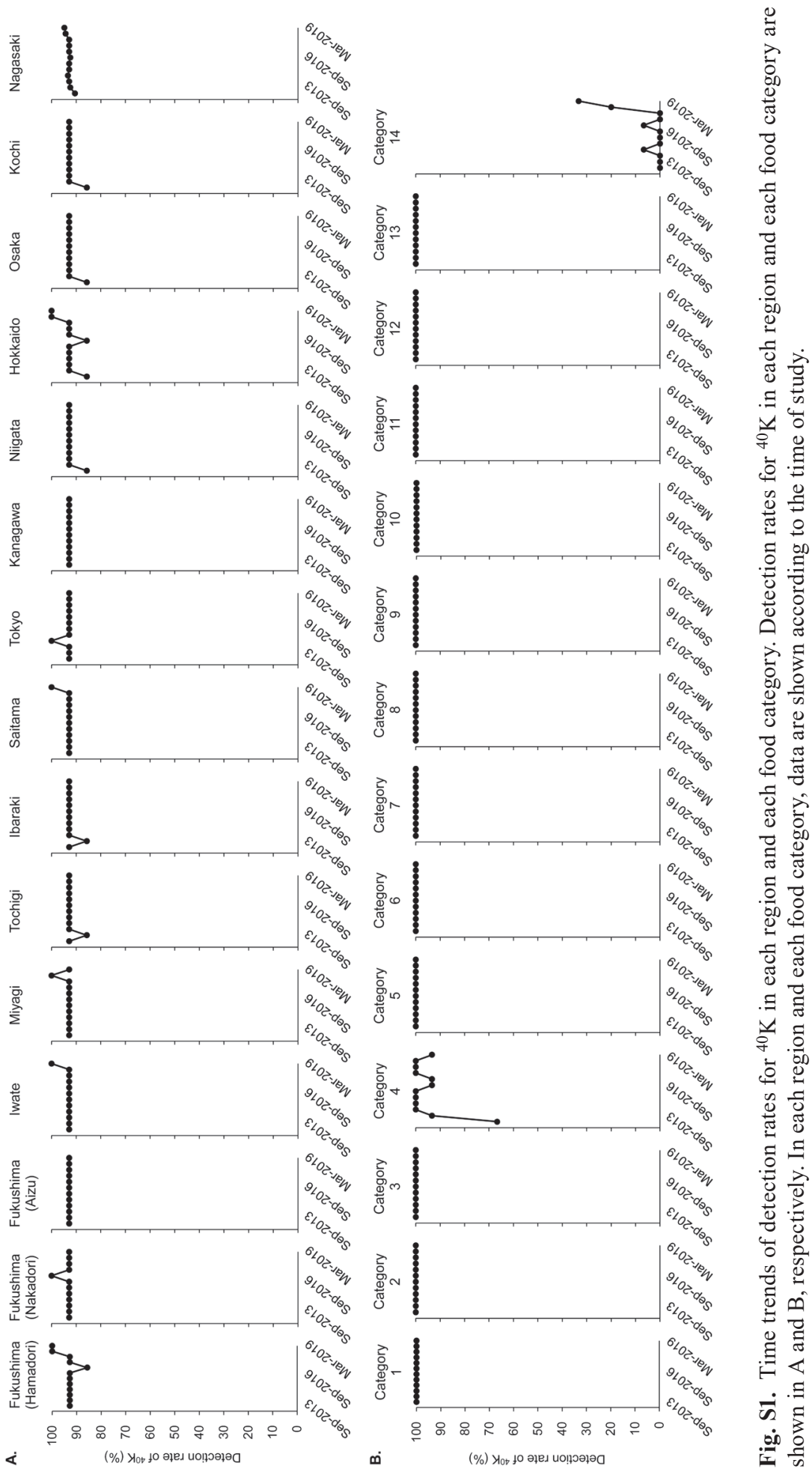




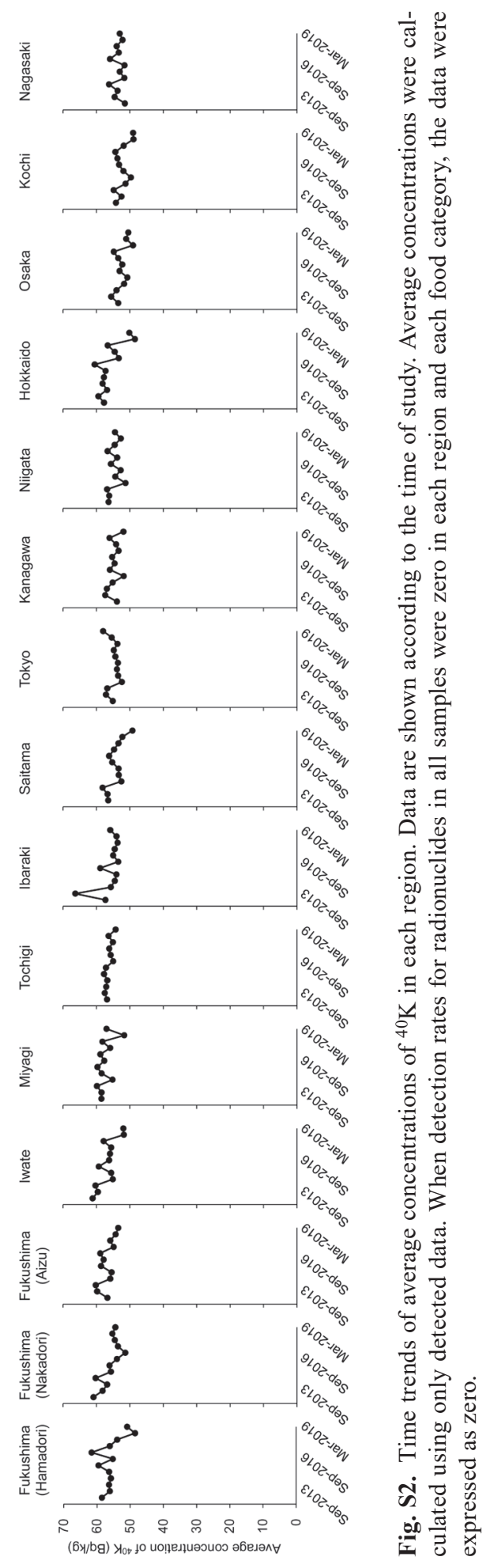

